\title{
Cambios territoriales y efectos producidos por la industria forestal sobre el anclaje de las comunidades locales en la Cuenca del Itata Chile Central $^{1}$
}

\author{
Hugo Romero ${ }^{1}$ y Carlos Fuentes ${ }^{2}$ \\ 'Departamento de Geografía de la Universidad de Chile y ${ }^{2}$ Escuela de Geografía de la Uni- \\ versidad de Chile
}
"El territorio es una expresión compleja que conjug a al medio y a los componentes y procesos que contiene: grupos sociales, relaciones, conflictos. Vale decir, el territorio tiene un continente y un contenido, no se reduce sólo a la complejidad de su continente fisico-natural". (BOZZANNO, 2000).

\section{RESUMEN}

A partir del modelo de Complejos Dinámicos, se analizan los cambios socio-territoriales en cuatro comunidades que se localizan a distancias crecientes del Complejo Forestal e Industrial Nueva Aldea, controvertido megaproyecto dedicado al procesamiento de madera, papel y celulosa, ubicado en el Río Itata, Región de Biobio. La disminución de la población, la pérdida de áreas cultivadas y la sustitución del bosque nativo son evaluados mediante datos censales, fotografías aéreas e imágenes satelitales, empleando sistemas de información geográfica, confirmándose que se trata de tendencias de degradación social y ambiental de larga data. Las plantaciones forestales y un incremento en la accesibilidad pueden ser considerados los mayores impactos territoriales asociados a la instalación de este proyecto. Se constata la existencia de nuevas expectativas y alternativas de desarrollo en las comunidades locales, especialmente en turismo rural y de intereses especiales, que deberían ser consideradas en forma integrada, sinérgica y estratégica por los sectores públicos y privados. Se presentan los discursos de los principales actores sociales con el fin de advertir sobre las contradicciones que complican la sustentabilidad territorial de estos mega proyectos de inversión.

Palabras clave: Complejos dinámicos, desarrollo forestal local.

\section{Spatial changes and effects produced by the forestal industry on the embededness of the local communities in the Itata Basin, Central Chile}

\section{SUMMARY}

Based on a Complex Dynamic model, land uses and social changes are analyzed in four local communities that are located at increasing distances from Nueva Aldea Forestry and Industrial Complex, a large investment devoted to process timber, paper and cellulose, a controversial project that has been recently located in Itata River, Biobio Region. Diminishing population, loss of cultivated areas and woodlands substitution, are assessed using census data, air photographs and satellite images, in a geographical information system. Social and environmental degradation could be considered as a long term trend while forest plantations and the improvement of accessibility could be assessed like the most relevant environmental impacts New expectations and development alternatives, like rural tourism and special interest tourism should be included in integrated, synergetic and strategic public and private plans. Speeches of the main social actors are presented, emphasizing contradictions which complicate the territorial sustainability of large projects in Chile.

Key Words: Dynamic complex, local forestry development.

1 Proyecto Mult 05-09/2 del Departamento de Investigación de la Universidad de Chile 


\section{INTRODUCCIÓN}

Los efectos de las grandes inversiones de capital destinadas a explotar intensivamente los recursos naturales en Chile, sobre las comunidades rurales, han sido materia de creciente preocupación, predominando la idea que han contribuido poco al desarrollo regional y local. Los megaproyectos mineros en el norte, de infraestructura, industriales y forestales en el centro, y forestales, pesqueros, conservacionistas e hidroeléctricos en el sur, destacan entre los emprendimientos que han, o están encontrando, severos problemas de parte de las comunidades locales. En todas las regiones se advierte la generación de conflictos y se aprecia una atmósfera de desencanto, incertidumbre y frustración ante la llegada de nuevas inversiones económicas. En Chile comienza a repetirse la situación observada en muchos otros lugares, por la cual los principales inconvenientes para instalar grandes proyectos de inversión no son de orden técnico o financiero sino que corresponden a crecientes conflictos entre los agentes inversores y la sociedad regional y local.

Hasta ahora, la única forma de estimar y prever estas conflictivas relaciones dialécticas entre las inversiones asociadas a la globalización de la economía nacional y las comunidades locales, corresponde a la Evaluación de Impacto Ambiental (EIA) de proyectos. Sin embargo, la EIA no evalúa territorios sino que proyectos individuales y no dispone de adecuadas líneas de base que permitan discriminar entre los procesos de cambio que ocurren históricamente en función de las tendencias naturales y socioeconómicas y los impactos que pueden ser atribuidos a proyectos o intervenciones específicos. La EIA tampoco considera los impactos acumulativos, es decir el efecto sinérgico y de largo plazo de las perturbaciones puntuales o sectoriales provocadas por proyectos específicos sobre las estructuras y funciones complejas e interactivas de la naturaleza y la sociedad que ocupa un territorio. En particular, la evaluación de los impactos sociales se restringe muchas veces a la simple consideración de aspectos demográficos y laborales, que desde luego no posibilitan comprender los efectos de las intervenciones sobre las complejas redes de relaciones sociales y culturales que asocian a las comunidades locales, a éstas con las redes regionales, y a todas ellas con el territorio.

Ante la incapacidad de los proponentes de los proyectos de inversión de comprender los complejos sistemas de relaciones sociales que asocian a las comunidades locales y las reacciones de éstas ante las amenazas de pérdida de recursos críticos, perturbaciones socio ambientales y debilitamiento de las estructuras culturales, las empresas privadas debido a la carencia de instituciones y programas públicos-, han asumido crecientemente papeles llamados de responsabilidad social, que la mayoría de las veces se confunden con filantropía o donaciones cosméticas destinadas especialmente a lavar su imagen corporativa, pero en ningún caso a asegurar la participación de esas comunidades en la toma de decisiones y en la distribución de los beneficios que hasta ahora se concentran casi exclusivamente en los empresarios y compañías privadas.

Tanto para los gobiernos como para las empresas, es cada vez más difícil prever y considerar los asuntos conducentes a anticipar y resolver conflictos sociales que pueden desembocar en impedimentos para instalar, construir y desenvolver sus iniciativas con normalidad. En realidad, la gestión del territorio por parte de las empresas públicas y privadas nunca ha considerado en forma real y efectiva la participación de las comunidades locales, cuyos sistemas de propiedad y tenencia de recursos se transforman más bien en una limitación para la instalación de sus proyectos o actividades. Presionados por las ideas de participación social, las empresas y los gobiernos han estado dispuestos a aceptar supuestamente su importancia, pero ello no ha ido acompañado de la generación de las instituciones que permitan organizar, canalizar y negociar los intereses de las comunidades así como implementar mecanismos 
de evaluación de intangibles, compensación por pérdidas de recursos, patrimonios y accesibilidad, o reparación de injusticias, predominando acciones superficiales de convocatoria e información al público, realizadas sólo para cumplir con la letra de las disposiciones legalés.

Es indispensable desarrollar nuevos enfoques para analizar y evaluar los grandes cambios productivos que experimentan los territorios y los lugares nacionales como consecuencia de la implantación local y regional de las redes y circuitos de la globalización. La geografía cultural y económica puede contribuir a conocer de forma más integrada los rasgos mayormente afectados por los megaproyectos, y que dicen relación con impactos muchas veces inadvertidos e irreversibles sobre los ecosistemas, las redes socio-culturales, los usos y coberturas de los suelos, los estilos de vida, las formas productivas, la propiedad y tenencia de los recursos críticos, como agua y suelos, y los sistemas de códigos conductuales, valóricos y cognitivos de las poblaciones locales.

Una manera de enfrentar integradamente los asuntos socioeconómicos y culturales dice relación con la territorialidad, comprendida como síntesis de conocimientos, valores y actitudes aprendidos socialmente, que comparten las personas que habitan permanentemente un lugar, entre las cuales destaca la identidad, expresada a través de modos de vida y códigos materiales y simbólicos, destinados a asegurar la permanencia y reproducción de la comunidad en sus lugares de residencia.

El desarrollo de la industria forestal en el país ha sido rápido y vigoroso durante las últimas décadas. Se espera que el año 2007 Chile ocupe el tercer lugar en el mundo en la exportación de celulosa, con una participación de $4,2 \%$ en el total mundial, ubicándose inmediatamente detrás de Canadá y Estados Unidos. En el año 2004, el total de productos forestales exportados generó 3.397 millones de dólares, lo que representaba aproximadamente el $10 \%$ de las exportaciones totales del país. Se espera que la participación del sector en la generación de divisas supere los 4.500 millones de dólares el año 2010 , lo que significa aumentar el número de plantas industriales y las superficies plantadas, que superaban los dos millones de hectáreas e] año 2004. (Serón, 2006).

La Región del Biobío es el espacio geográfico forestal más importante del país. Aporta el $44 \%$ de las plantaciones nacionales, el $58 \%$ de la producción total del país de madera aserrada, $67 \%$ de celulosa, $83 \%$ de tableros $y$ chapas y el $76 \%$ del embarque de exportaciones forestales.

Según los representantes empresariales (Serón, 2006), el sector forestal genera 123.000 puestos de trabajo en forma directa y 315.000 en forma indirecta, lo que significa que 1.340 .000 personas o el $9 \%$ de la población total del país dependerían de estas actividades. En el caso de la región de Biobío, las cifras corresponderían a 63.000 empleos directos y 118.000 indirectos, lo que involucraría a un total de 551.000 personas, - 30\% de la población regional. Las cifras hablan por sí solas de la enorme relevancia económica y social del desarrollo forestal para el país y la región del Biobío, de lo cual resulta en parte la importancia de realizar investigaciones sobre sus efectos a escala local, que permitan "anclar" o territorializar sus costos y beneficios, socioeconómicos, culturales y ambientales.

El presente trabajo explora en una primera sección algunos aspectos de las transformaciones en los usos y coberturas de suelos de un conjunto seleccionado de comunidades rurales localizadas a distancias crecientes del lugar de instalación del Complejo Forestal e Industrial (CFI) Nueva Aldea: Nueva Aldea, Guarilihue, Cerro Negro y La Leonera. Mediante análisis multitemporales de fotografías aéreas e imágenes satelitales y a través de validaciones de terreno, se analizan los cambios de usos y coberturas de suelos observados entre 1978, 1994, 1998 y 2005. Estos análisis se complementan con la consideración de los patrones socio-demográficos 
y los cambios en accesibilidad que enfrentan las localidades del Valle del Itata, donde se instala actualmente el mayor complejo industrial y forestal del país.

Una instalación de la envergadura del Complejo Industrial y Forestal Nueva Aldea es el resultado de una planificación e implementación de largo plazo, de carácter estratégico, absolutamente necesario de realizar por parte de las empresas proponentes, considerando el volumen de capital y tecnología invertidos, cercano a los 1.400 millones de dólares. Es posible indicar que la implementación del proyecto comenzó hace décadas mediante las primeras plantaciones de las superficies forestales que proporcionarían la materia prima a la industria y en el transcurso del tiempo asociaron la construcción de la infraestructura vial y portuaria, de tal manera que la localización elegida para la planta ha representado un ejercicio complejo de geografía aplicada. No obstante, no ha existido una planificación estratégica equivalente de las políticas e intervenciones públicas que de cuenta de las transformaciones territoriales, ambientales, sociales y culturales que desencadenan este tipo de proyectos sobre las comunidades locales. Ni mucho menos planes y programas públicos de carácter estratégico, destinados a relacionar positivamente al capital natural, social y cultural de la región con el creciente desarrollo de la industria forestal. Esta dicotomía aparente entre el actuar de los sectores privado y público indica la desvinculación entre las escalas globales y locales y se constituye en uno de los mayores desafíos que deberá enfrentar el país para conseguir un auténtico proceso de anclaje territorial de los beneficios sociales y económicos en los lugares donde se ejecutan las inversiones y se concretan los proyectos.

Por otro lado, los alcances espaciales y temporales de las transformaciones son difíciles de precisar en este tipo de megaproyectos. Si bien los impactos de los proyectos de inversión sobre el medio natural y social pueden ser estimados a partir de modelos y monitoreos sistemáticos y especializados, los cambios sobre los sistemas socio territoriales y socio ambientales, pueden haberse estado manifestando desde mucho antes y en forma gradual y persistente, como sucede con las condiciones prevalecientes en el secano costero de las regiones mediterráneas de Chile, caracterizadas por altos niveles de pobreza, carencia de agua, postergación tecnológica, emigración de las poblaciones y deterioro de las condiciones ambientales. En estos casos, es especialmente entendible que tanto las autoridades públicas como las comunidades locales cifren sus expectativas en torno a estas mega inversiones creyendo que pueden contribuir por sí solos, a resolver en parte o en su totalidad, problemas y procesos históricos que explican una realidad de pobreza y exclusión de larga data.

Por otro lado, es sabido que los megaproyectos ofrecen empleo a los habitantes de las comunidades locales cercanas especialmente durante el período de construcción de las infraestructuras e instalaciones industriales, momento en que se requiere mano de obra no especializada. Con ello, los habitantes locales abandonan los trabajos del campo para acceder a ingresos más elevados pero efímeros. $\mathrm{Al}$ abandonar el campo, aunque en forma temporal, se pueden generar condiciones que estimulen la migración definitiva hacia las ciudades. Es dable esperar que la decisión definitiva de emigrar se relacione con las alternativas de empleo que se puedan generar en el lugar para complementar los bajos salarios que se obtienen regularmente en estas áreas rurales, y que ello se vea afectado por el decaimiento-distancia entre los lugares de residencia de las comunidades y los proyectos industriales. Parece ser muy relevante que los agentes privados y públicos exploren las posibilidades de generar en el territorio las condiciones para fortalecer y salvaguardar las organizaciones y los territorios locales de los cuales depende la cultura y los sistemas de vida rurales, aunque ello implique invertir en acciones complementarias a las actividades sectoriales que representan.

La vertiente institucional de la geografía económica puede contribuir a analizar las relaciones entre la economía global y los 
territorios, mediante el concepto de embeddedness. Embeddedness puede ser traducido como "anclaje", es decir como la capacidad generada por las instituciones y redes sociales locales para asegurar que los beneficios que puedan originarse en la incorporación de sus lugares a los circuitos globales de comercio y capitales, sean retenidos espacialmente, $\mathrm{y}$ resulten funcionales al desarrollo socioeconómico de los primeros.

Romero (2004), ha traducido embededness como "embuimiento" o capacidad de los "lugares-locales", de transformarse en "lugares-globales" (Falçao Vieira y Falçao Vieira, 2003; Romero y Azócar, 2004) o bien de tornar exitosa la relación dialéctica entre los planos de la economía global y los "milieu" de la economía local (Conti, 1997). Una adecuada relación entre ambos planos espaciales se debería expresar en la capacidad de generar desarrollo endógeno, mediante una combinación virtuosa de la máxima especialización productiva con la máxima integridad cultural, o, por el contrario, aumentar la dependencia y vulnerabilidad de los lugares en la medida que una escasa especialización e inserción a los flujos globales se asocia a una mayor desestructuración de la cultura y sociedad local.

Bebbington (2003) ha propuesto que para la geografía del desarrollo, es necesario que las narrativas esencialmente negativas que existen respecto al impacto de los flujos de capitales globales sobre las regiones y lugares, sean analizadas con mayor rigurosidad, teniendo en-cuenta que así como existen numerosas experiencias nefastas en la región, también se observan casos exitosos, pareciendo que las diferencias entre ambas se deberían esencialmente a la existencia de mecanismos e instituciones sociales que intervengan favorablemente en los procesos de transferencia del capital financiero global a la generación de capital social y cultural en los lugares y comunidades locales.

\section{EL PROBLEMA Y SUS CATEGORÍAS DE ANÁLISIS}

Una de las cuestiones geográficas más dramáticas asociadas al modelo de desarrollo económico seguido en Chile dice relación con el carácter de enclave que asumen en el territorio las grandes instalaciones asociadas a los megaproyectos de inversión. Espacios reducidos, correspondientes a yacimientos mineros y plantas industriales, por ejemplo, concentran enormes cantidades de capitales, tecnologías e informaciones, mientras que los espacios que los rodean pueden permanecer aislados, completamente al margen de la modernidad y sumidos en la pobreza. El espacio de la globalización se expresa esencialmente como sistemas de redes que conectan eficientemente los nodos o enclaves, mientras que los espacios intersticiales permanecen desconectados y marginalizados.

La altísima concentración espacial de las plantaciones y actividades forestales industriales especializadas en la región del Bíobío (Romero y Azócar, 2004), puede ser explicada como una expresión cabal de la capacidad de ciertos lugares por atraer capitales nacionales e internacionales. Las favorables características del sistema natural de la región contribuyen a explicar esta alta especialización productiva: un clima mediterráneo con lluvias abundantes en invierno con una marcada estación seca, que recibe alta radiación solar y temperaturas, asegura una elevada productividad biológica de los bosques de rápido crecimiento, representados por cientos de miles de hectáreas de superficie plantada con pinos y eucaliptos; pendientes suaves de la Cordillera de la Costa que clasifican como de aptitud forestal, sumado a la existencia de numerosos y caudalosos ríos, esteros y quebradas, que aseguran un importante abastecimiento de agua, que no se encuentra en los valles ubicados más al norte del país. 
Laderas suaves y cercanía al mar facilitan la construcción de caminos y con ello una alta conectividad a un sistema portuario cercano, amplio, diversificado y moderno, al cual se unen los terrenos interiores por un eficiente sistema de carreteras, constituyendo la presencia de la infraestructura una de sus principales ventajas competitivas.

Dado este importante conjunto de ventajas comparativas y competitivas, y sumada una temprana decisión gubernamental por forestar sus terrenos, no resulta extraño inferir que la región está destinada no sólo a sostener, sino que a incrementar sus áreas plantadas y su especialización productiva en las actividades forestales. En la medida que aumentan las plantaciones y se van agregando superficies con bosques maduros y maderables, aumentan también las instalaciones industriales, especializadas en la fabricación de celulosa y pulpa primeramente, y más recientemente en la elaboración de productos de la madera, tales como tableros, muebles, puertas, etc., además del desarrollo de la industria del papel. Entre los efectos de estas instalaciones industriales, destacan su significativo aporte a la obtención de divisas por parte del país y el aumento de la infraestructura y equipamientos regionales y con ello el mejoramiento de la accesibilidad y utilidad de los lugares; recuperación de suelos y tierras erosionados; contribución al combate contra el cambio climático por substracción de gases invernadero, y número considerable de empleos directos e indirectos, algunos de los cuales corresponden a mano de obra especializada y por ello, de altos ingresos. Los salarios de la mano de obra ocupada en el sector y de las empresas destinadas a satisfacer su demanda de servicios e insumos, influyen positivamente en el aumento de la demanda interior por bienes y servicios, y en la construcción de industrias, viviendas y caminos.

El paulatino incremento de las actividades industriales, por sobre las de extracción o escaso procesamiento industrial, aumenta el valor agregado, la demanda de insumos locales y el surgimiento de encadenamientos productivos, así como la diversidad y com- plejidad de los mercados urbanos, lo que ha favorecido la expansión de las ciudades y la instalación de servicios y funciones cada vez más complejos y diversos (Azócar et al., 2007).

Entre los impactos negativos mayores destacan la emigración de las poblaciones rurales y el drenaje de los beneficios económicos hacia regiones centrales; extraordinaria dependencia de los mercados y precios internacionales; escaso valor agregado de la producción; creciente competencia con otros sectores por el control y propiedad de recursos críticos, tales como el agua, los territorios de mayor accesibilidad y los paisajes; pérdidas de biodiversidad; contaminación del aire, aguas y suelos -en particular por parte de las industrias instaladas en las décadas pasadas, cuando no existían exigencias ambientales legales-; sustitución de otras actividades económicas socialmente más rentables en las áreas rurales y redundancia de la mano de obra; abandono de tierras por parte de la población de pueblos rurales por falta de trabajo; bajos salarios; informalidad y temporalidad del empleo subcontratado; incremento de la segregación social y de la marginalidad de las áreas urbanas y rurales, etc.

Sintetizando la discusión sobre el desarrollo forestal, los argumentos favorables se relacionan especialmente con las ventajas y beneficios económicos del sector, mientras que los argumentos críticos se focalizan en aspectos socio-culturales y ambientales. Parece ser necesario intentar examinar con mayor profundidad estos discursos, así como disponer de ciertas bases objetivas sobre los reales cambios territoriales que han venido ocurriendo en las áreas donde se instalan los megaproyectos, considerando un tiempo considerable, que facilite discriminar entre las tendencias que han continuado teniendo lugar con o sin proyectos y aquellos que indudablemente pueden ser asociados a la industria.

Como una forma de contribuir a una discusión más compleja y equilibrada, Floysand (2005) ha propuesto que los flujos externos de 
capital que arriban a las regiones sean vistos -más allá de las mediciones econométricas-, como un sistema complejo de capital, actores y conocimientos. Cada uno de estos pilares debe ir acompañado de sus correspondientes enfoques analíticos: capital-desarrollo; campos sociales-actores discursos-conocimientos. Floysand (op.cit) ha señalado que "Un enfoque a través del complejo capital, actores, conocimiento, permite que las investigaciones de sus efectos vayan más allá de los análisis económicos cuantitativos y se dirijan hacia el terreno de los anclajes espaciales de las inversiones. Esto es lo que se denomina complejos dinámicos; aquellos análisis econométricos que incluyen problemas sociales contemporáneos como poder, desarrollo regional y pobreza".

La importancia de los conceptos postmodernos elaborados por la geografía, se encuentra en gran medida subyaciendo al complejo capital-actores-conocimientos. Estos enfoques contemporáneos del espacio geográfico centran su atención en los elementos culturales, sus percepciones y representaciones. Los elementos culturales corresponden a un complejo sistema de valores, conductas y símbolos, es decir, de componentes esencialmente inmateriales, que, sin embargo, condicionan fuertemente el comportamiento espacial de las sociedades. Dentro de las representaciones simbólicas de la realidad, una parte importante se expresa a través de narrativas, discursos y metáforas. La geografía cultural (Claval, 2003) sostiene que es través de esos discursos y metáforas, donde se aprecia el significado de la verdadera comprensión e interpretación de los conceptos tales como territorio, desarrollo sustentable y medio ambiente. A la descripción exhaustiva y a la explicación de las relaciones causales entre los diversos componentes del medio ambiente natural y socio-cultural, debe agregarse el interés por entender la totalidad del espacio geográfico, lo que implica incluir los sistemas sociales y culturales de valores, finalidades y numerosos prejuicios, mitos y leyendas, que conforman los denominados heteroespacios (Vallega, 2000; Romero, 2001).
En otras palabras, tan importante como tratar de descifrar las relaciones físicas, químicas o biológicas que vinculan a los componentes del sistema ecológico y a éstos con la sociedad, y a ambos en el territorio, es intentar comprender e interpretar las relaciones existentes entre los individuos y las comunidades respecto a cómo observan, organizan y actúan frente a la naturaleza, la sociedad y el medio ambiente. Cuando los individuos intentan decodificar los significados y símbolos con que se aprecia y maneja al medio ambiente, existen mayores posibilidades de aproximarse al verdadero sentido humano del territorio y percibir los diversos y muchas veces contradictorios intereses que orientan y subjetivan el quehacer y los objetivos de los actores. Para Hägerstrand (2003), los discursos y metáforas guían la formulación de planes y programas de las instituciones de nivel central y sectorial, pero son las empresas y las comunidades las únicas organizaciones que actúan directamente a escala local, es decir los únicos actores que realmente intervienen en el territorio y gestionan el medio ambiente, principalmente a través del ejercicio de los derechos de propiedad sobre los bienes y servicios ambientales.

Para Picket (2004), la resiliencia ambiental forma parte de las metáforas que guían a través de modelos y conceptos las posibilidades de desarrollo sustentable, en la medida que la ecología se aleja de los conceptos tradicionales de equilibrio armónico y preservación de la naturaleza, para considerar las situaciones ambientales de cambio, perturbaciones e inestabilidad permanentes en las relaciones naturaleza-sociedad, y el carácter de las fuerza directrices socio-económicas-culturales, que terminan siendo tanto o más relevante que las directrices biogeofísicas en el comportamiento de los sistemas de recursos y de los ecosistemas.

El desafío para el estudio de las inversiones directas de capital es determinar cómo el complejo capital-actores-conocimientos está anclado en las escalas espaciales, y cómo influye sobre los resultados de las inversiones 
sobre el poder, el desarrollo regional y la pobreza, en otras palabras, cómo los eventos y procesos a escalas global, nacional, regional y local, se combinan para crear complejos dinámicos (Jacobsen, Rusten and Floysand, 2005)

La Teoría del Discurso asume que las relaciones de poder pueden ser investigadas a través de lo que Neumann (2001) llama las "condiciones existentes para la acción", o que Foucault (2003) denomina como "reglas de formación de las afirmaciones". El estudio de las inversiones directas de capital, como discurso, se enfoca en la relación conocimientos-capital-actores e incluye investigar sobre cómo se articulan las primeras con estas últimas y sobre cómo se reproducen en los complejos dinámicos, a través de las diversas escalas espaciales (Floysand, 2005). Las formas en que las inversiones de capital como discurso producen relaciones de poder son poco conocidas, como también se desconoce cómo las luchas entre actores globales, regionales y locales pueden influir sobre el discurso de las inversiones directas, llegando incluso a impedirlas o paralizarlas, cómo ha ocurrido con la privatización del agua en Bolivia, con la instalación de megaproyectos mineros en Perú o con la imposibilidad de iniciar la construcción de una planta de aluminio en Aisén.

En el análisis del anclaje espacial se asume que los actores locales están simultáneamente amarrados a diversos sistemas de relaciones (organizaciones), que actúan a diferentes escalas geográficas. El concepto de campos organizacionales comprende a "aquellas organizaciones que en su conjunto constituyen un campo reconocido de vida institucional: proveedores claves, consumidores de productos y recursos, agencias regulatorias, y otras instituciones que producen similares productos y servicios (Powell and Di Maggio, 1991). La noción de campo connota la existencia de una comunidad que participa de un sistema común de significados y cuyos participantes interactúan más frecuente y amistosamente unos con otros que con agentes situados fuera del campo (Scott, 1995).
El análisis del anclaje espacial del desarrollo en áreas impactadas por las inversiones directas de capital descansa en el concepto de espacios-tiempos relacionales o campos sociales que pueden ser identificados examinando la durabilidad de las relaciones entre agentes y las tareas específicas que son resueltas por las prácticas asociadas. Una red de relaciones sociales llega a ser un campo social cuando conforma una red de resolución de tareas que produce, mantiene o cambia a las personas sociales y/o a parte de la sociedad. Un campo social representa un patrón relativamente denso de relaciones sociales que constriñen y permiten la agencia de los actores. Las personas sociales o grupos de personas sociales están anclados en un amplio rango de campos sociales interrelacionados y por ello, las inversiones directas de capital en las regiones tienen relaciones con diversos campos sociales al mismo tiempo.

En cada campo social se encuentran prácticas sociales que producen significados intersubjetivos compuestos de categorías, narrativas y reglas de conducta que los miembros del campo usan para interpretar, mantener y generar nuevos significados. La producción de significados origina bienes no transables tales como reglas de conductas, que pueden ser formales e informales. Mientras las reglas formales están escritas y comprenden derechos y obligaciones de las personas y las organizaciones, las informales pueden corresponder a expectativas en el tiempo-espacio de una comunidad acerca del desempeño de una empresa.

Las inversiones directas de capital se sitúan en un sistema de campos sociales, correspondientes a diferentes escalas geográficas. Algunas inversiones están ancladas en campos sociales constituidos por proveedores locales especializados, y dependen de campos globales de clientes y proveedores no especializados. Otras inversiones están ancladas a campos globales y dejan poco espacio para establecer relaciones con firmas locales. En este último caso, la importancia de las redes locales ante las inversiones será modesta y la provisión de materias primas, servicios y 
mano de obra especializada, serán los únicos beneficios para la región. Otras inversiones están fuertemente ancladas en campos sociales que son locales, promoviendo las innovaciones y el desarrollo regional.

Por último existe el anclaje espacial de la pobreza, que también orienta el análisis de las inversiones directas. La necesidad de que los gobiernos regulen las inversiones directas de capital a través de requerimientos de desempeño (aportes de infraestructuras, políticas de fomento de las exportaciones y de transferencia tecnológica) y de incentivos a la inversión, tales como préstamos y exención de impuestos, se pueden evaluar a través de sus efectos sobre el desarrollo (empleos directos e indirectos, transferencia de conocimientos), por un lado, y por otro, por el efecto de dependencia (aumento de la dependencia del capital extranjero y drenaje de recursos hacia el exterior). En otras palabras, las inversiones directas de capital pueden producir efectos contradictorios. La mayoría de los teóricos señalan que las inversiones basadas en los recursos no generan un desarrollo positivo en los países o regiones receptoras, pero existen evidencias que demuestran lo contrario, lo que obliga a analizarlas a través de los complejos dinámicos capital-actoresconocimientos.

\section{METODOLOGÍAS}

Las comunidades seleccionadas se ubican a distancias crecientes del sitio de instalación del Complejo Forestal e Industrial Nueva Aldea y fueron elegidas por presentar ciertos rasgos culturales comunes en forma evidente, tales como usos del suelo característicos, programas y eventos culturales y organizaciones locales especialmente asociadas al ámbito productivo y social. Para la obtención de los datos socio-demográficos de los años 1982, 1992 y 2002 a escala de las comunidades seleccionadas, se recurrió a los Censos de Población y Vivienda del Instituto Nacional de Estadística (INE), procesados mediante el Programa Redatam.
Los años para realizar los análisis de cambios y coberturas de suelos dependieron de la existencia de fuentes cartográficas. Se contó con fotografías aéreas correspondientes a los años 1978, 1994 y 1998. Ante la imposibilidad de disponer de fotos aéreas más recientes, se empleó una imagen satelital LANDSAT TM existente para el año 2005. Las imágenes aéreas y satelital fueron georreferenciadas e ingresadas a un Sistema de Información Geográfica como series multitemporales. La tipología de usos y coberturas de suelos incluyó clases específicas que derivan de cuatro categorías generales, según lo indicado por el Proyecto CORINE Land Cover de la Unión Europea: asentamientos rurales y superficies construidas, áreas forestales, terrenos agrícolas y superficies ocupadas por cuerpos de agua.

Los análisis de accesibilidad se han desarrollado considerando los métodos empleados por Romero y Órdenes (2003) y consisten en la clasificación de áreas accesibles e inaccesibles, considerando la existencia de buffers en torno a los caminos regionales, jerarquizados según sus características viales.

Los análisis de discursos de los actores corresponden a una síntesis y clasificación, realizada por los autores de este artículo, sobre la base de las presentaciones realizadas por representantes de las empresas forestales, organismos de gobierno, académicos y municipalidades, directamente involucrados en la instalación del CFI Nueva Aldea. Dichas presentaciones formaron parte del Seminario "La Industria Forestal en la Región del Bíobío", Visiones de distintas perspectivas, organizado por el Centro EULA de Ciencias Ambientales de la Universidad de Concepción y realizado en Diciembre de 2005 (Parra y Acuña, editores, 2006).

\section{RESULTADOS}

\section{El Complejo Forestal e Industrial Nueva Aldea}

El Complejo Forestal e Industrial Nueva Al- 
dea consiste en una inversión de US $\$ 1.400$ millones, de los cuales US $\$ 1.000$ millones están destinados a activos industriales y el resto a plantaciones forestales, que se localizan en 120 Há en la confluencia de los ríos Nuble e Itata, en la región de Bíobío (fig.1). La materia prima requerida alcanza a 10.000 $\mathrm{m} 3 /$ día de rollizos, de los cuales un $77 \%$ están destinados a la fabricación de celulosa. La suma total anual de rollizos requeridos corresponde a $3.356 .000 \mathrm{~m} 3$, de los cuales 2.810 .500 son destinados a la fabricación de celulosa.

El complejo industrial incluye cuatro plantas principales: la planta de trozado espera producir $1.200 .000 \mathrm{~m} 3 /$ año, la de fabricación de celulosa blanqueda, con capacidad de producir 550.000 ton/año; el aserradero, que producirá $400.000 \mathrm{~m} 3 /$ año de madera aserrada y la Planta de Molduras, capaz de producir 80.000 $\mathrm{m} 3 /$ año de madera elaborada. El consumo total de agua alcanza a $810 \mathrm{l} / \mathrm{s}$ y explica la localización estratégica del proyecto inmediatamente en la confluencia de ambos ríos, así como la preocupación permanente que ha existido por el vertido de aguas contaminadas al cauce fluvial, que podría afectar la calidad de las aguas de riego que son empleadas por numerosas comunidades rurales ubicadas en la parte baja de la cuenca del Itata (comunas de Trehuaco, Coelemu y Cobquecura).

El Estudio de Impacto Ambiental (EIA), identificó 58 impactos, de los cuales 45 eran negativos. Los 13 impactos positivos se relacionaban con el medio socioeconómico, destacando el aporte del proyecto al Producto Interno Bruto Nacional y Regional, la absorción de mano de obra, el uso de tecnología moderna y los aportes por compensación que recibirían las comunidades locales.

Los principales impactos socioeconómicos negativos identificados decían relación con una significativa reducción de los terrenos y mano de obra destinados a la producción agrícola en general y del sector vitivinícola en particular, debido a los cambios de usos del suelo de agrícolas a forestales, la pérdida de mercados nacionales e internacionales por la eventual contaminación de las tierras y los cultivos y cambios en la propiedad y tenencia de recursos críticos, tales como agua y tierras. Entre los impactos sobre el medio natural destacaban los problemas de conservación de la naturaleza, debido a las alteraciones en la distribución y abundancia de especies, la asimilación por parte de las especies biológicas que habitan los cauces fluviales de sustancias potencialmente tóxicas aportadas por los efluentes industriales, la pérdida de calidad del aire causada por el vertido de toxinas a la atmósfera y la alteración y deterioro en las formas, texturas y color del paisaje geográfico.

Los problemas asociados a la eventual escasez y contaminación del agua por vertidos industriales y los antecedentes existentes sobre los efectos de la instalación de otras plantas de celulosa en el país, han concentrado las críticas al proyecto, obligando a diseñar un ducto que los transporte hasta la costa, donde a su vez, se han generado conflictos con las comunidades de pescadores y mariscadores artesanales de Cobquecura, por ejemplo, y respecto a los efectos que pueda generar sobre la conservación de lobos marinos y el desarrollo del turismo en dicho lugar.

Ante los conflictos surgidos, la empresa propietaria del complejo industrial ha ofrecido compensaciones a las comunidades locales equivalentes a tres millones de dólares. Los fondos destinados a la inversión agrícola financian un programa de gestión de recursos hídricos y suelos en la comuna de Ranquil, el control de erosión de cárcavas en los suelos, el establecimiento de 50 Hás de frutales para pequeños agricultores en Ranquil y la entrega de doscientas mil plantas de cepas finas a los vitivinicultores interesados.

Los fondos de compensación incluyen además la implementación de un Centro de Exposición de Artesanía Local en Quinchamalí, la capacitación y difusión de las artesanías y obras de infraestructuras deportivas y recreativas en las comunas de Nipas, Portezuelo y Trehuaco. También consideran la capacitación de la mano de obra local para 
que se desempeñen en el CFI, programas de nivelación de enseñanza de adultos y la ejecución de proyectos educativos con énfasis en la formación silvícola.

\section{Cambios en la población total y ocupada por ramas de actividad económica}

La figura 1 presenta el área de estudio y la distribución de las comunidades seleccionadas y la figura 2, la distancia que las separa del Complejo Forestal e Industrial Nueva Aldea. Mientras la comunidad de Nueva Aldea se encuentra en la cercanía inmediata del proyecto, las comunidades de Guarilihue y Cerro Negro lo hacen en el tramo de 20 a $25 \mathrm{Km}$. de distancia y la Comunidad de La Leonera se localiza más alejadamente, sobre los $35 \mathrm{Km}$. Un supuesto común del análisis geográfico consiste en emplear la curva decaimiento-distancia, por la cual las interacciones espaciales entre dos objetos disminuyen en forma regular a medida que aumenta la distancia entre ellos. Consecuentemente, se espera que los efectos del Complejo Forestal sean mayores sobre la comunidad de Nueva Aldea y disminuyan gradualmente hacia el resto de las comunidades seleccionadas.

La figura 3 presenta la evolución de la población de las comunidades de acuerdo a los censos practicados en 1982, 1992 y 2002. Nueva Aldea y Cerro Negro han mantenido casi inalterable su escasa población en torno a los 200 habitantes, mientras La Leonera ha reducido aún más sus pocos residentes. Guarilihue, que concentra la mayor cantidad de población en el conjunto de las comunidades seleccionadas, ha presenciado también una reducción. Las cifras de variación intercensal registradas, permiten aseverar que se trata de comunidades locales escasamente pobladas y con tendencia a la disminución sistemática de sus habitantes, tal como corresponde a las localidades rurales del país en general y a las ubicadas en el secano costero de la región del

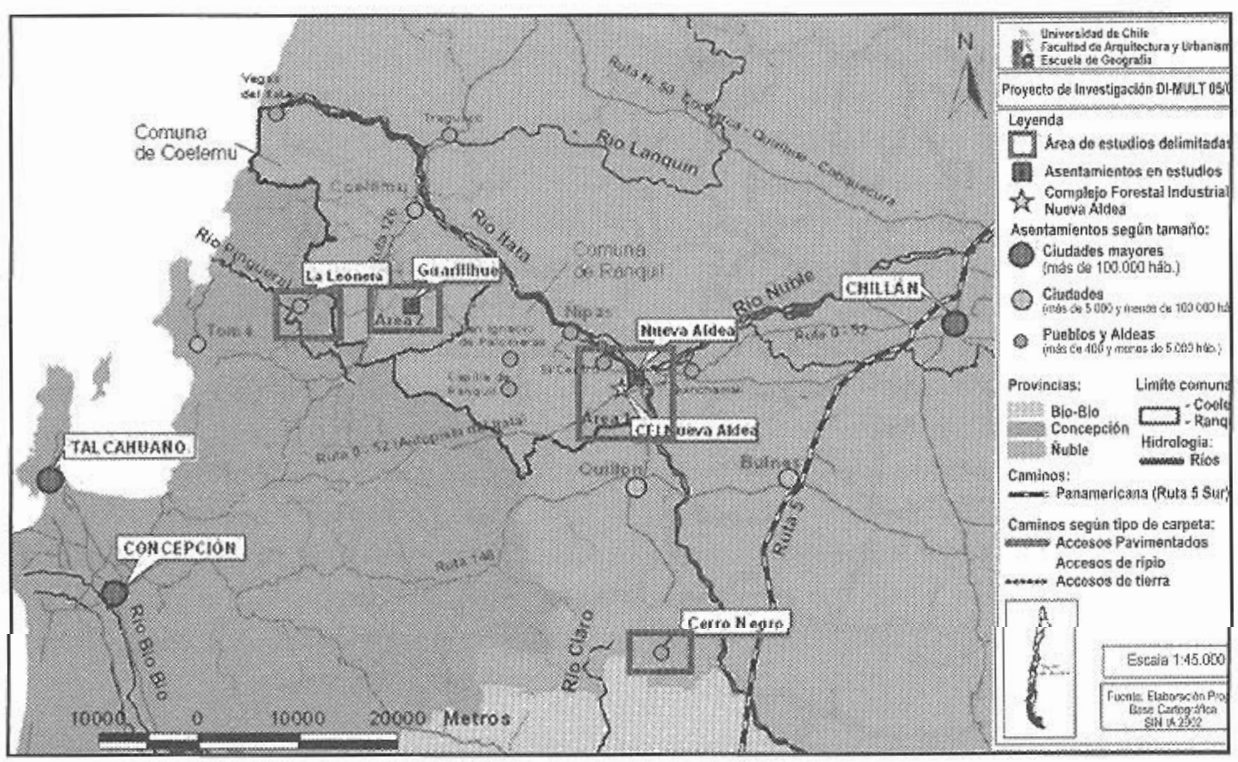

Fig. 1. Área de Estudio 
Fig. 2

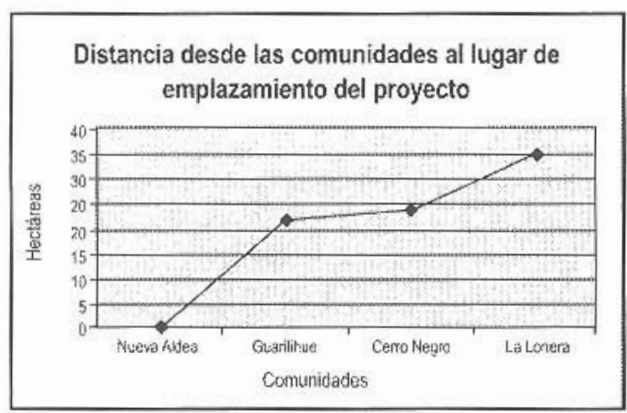

Fuente: Elaboración propia

Bíobío en particular.

Las figuras 4, 5, 6 y 7 presentan las variaciones intercensales de la población ocupada por ramas de actividades cconómicas entre 1992

Fig. 4

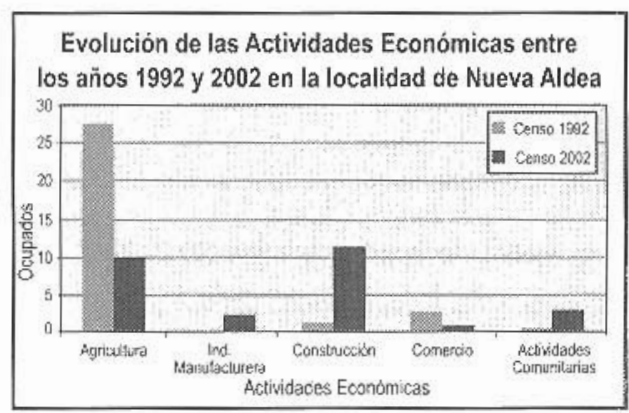

Fig. 6

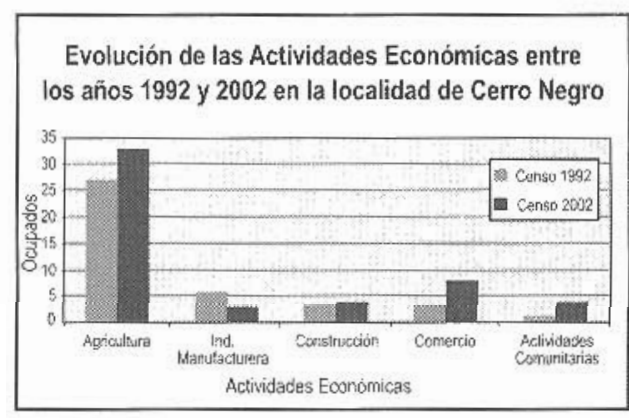

La principal diferencia en el empleo que brindan estas comunidades locales, la constituye el importante aumento de la población ocupada en construcción en Nueva Aldea, lo cual es considerado un impacto directo
Fig. 3

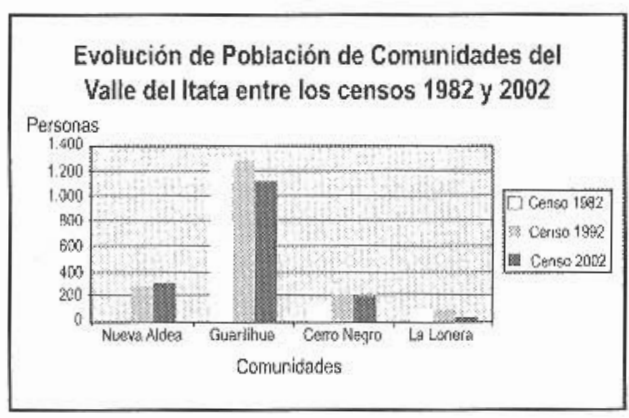

Fuente: En base a estadísticas INE

y 2002. Como se aprecia, en las comunidades locales, con excepción de Cerro Negro, la población ocupada en agricultura disminuyó significativamente, especialmente en el sector de Guarilihue y Nueva Aldea.

Fig. 5

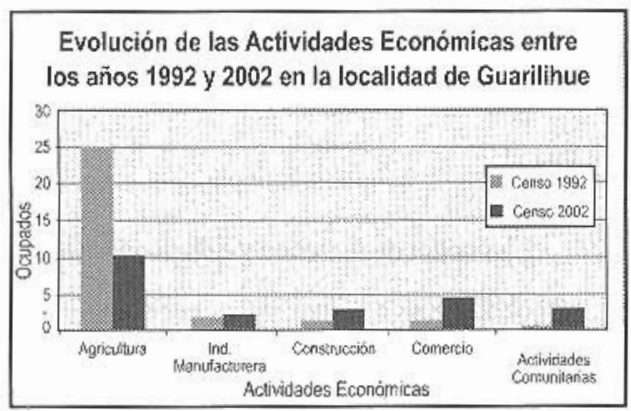

Fig. 7

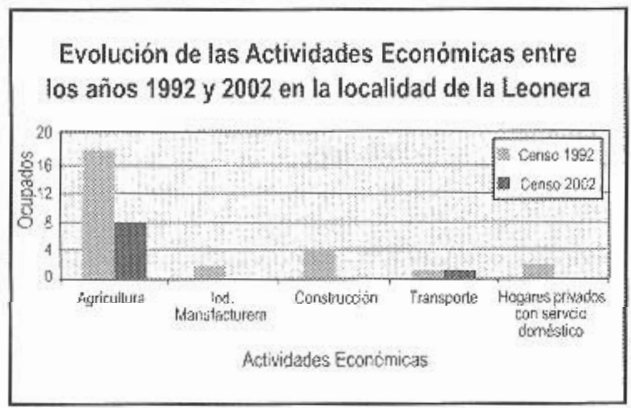

de la construcción de CFI. Sin embargo, es evidente que se trata de un fenómeno transitorio, como se observa en la figura $8 \mathrm{El}$ comercio y las actividades comunitarias se observan también como fuentes de empleo relevantes en las comunidades de Nueva Aldea y Guarilihue. 
Fig. 8. Mano de obra utilizada en la etapa de construcción Proyecto CFI Itata, 2004 (Primer a trigésimo quinto mes)

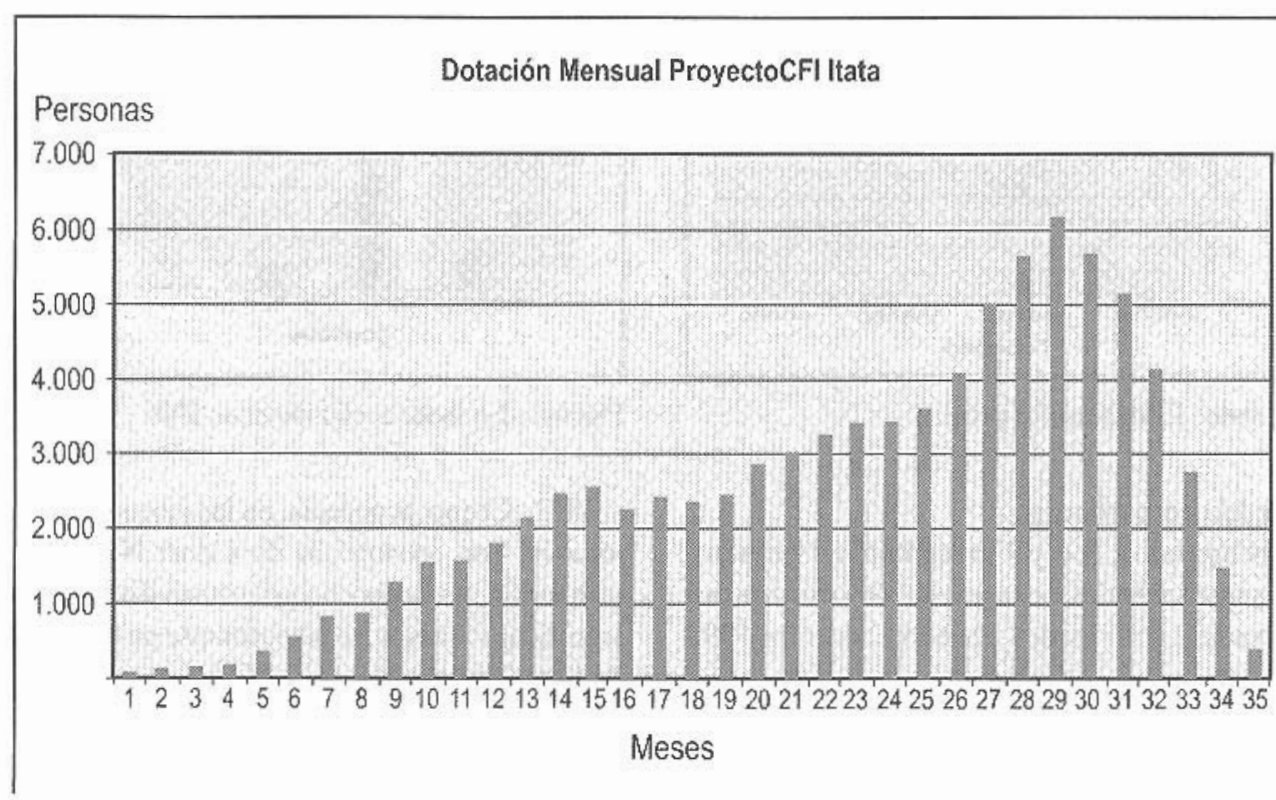

Fuente: Jaime Illanes y Asociados Consultores S.A.

Fig. 9.

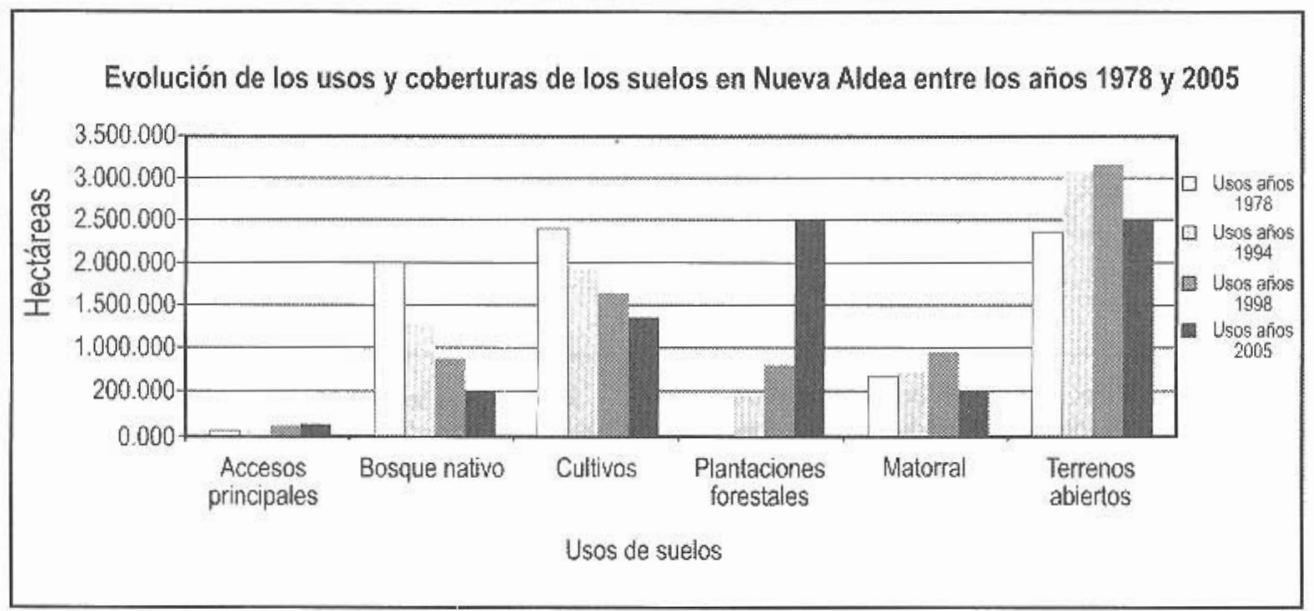

Fuente: Elaboración Propia.

Cambios en los usos y coberturas de las tierras

Para el análisis temporo-espacial de los efectos del complejo industrial forestal sobre las características socioculturales de las comunidades locales, es relevante realizar un análisis

pormenorizado de los cambios en usos y coberturas de las tierras. La Figura 9 presenta el caso de Nueva Aldea, siendo posible observar de inmediato la disminución de las superficies ocupadas por bosques nativos y cultivos y la 
mayor variabilidad de las tierras ocupadas por terrenos abiertos y los matorrales y bosques de baja cobertura. En términos espaciales, en 1978 (Fig. 9.1.) el bosque nativo era la cobertura predominante, distribuido sobre los sistemas de laderas montañosas y sobre espacios inaccesibles. Los bosques nativos

Figura 9.1 Usos y coberturas de suelos año 1978. Sector Nueva Aldea

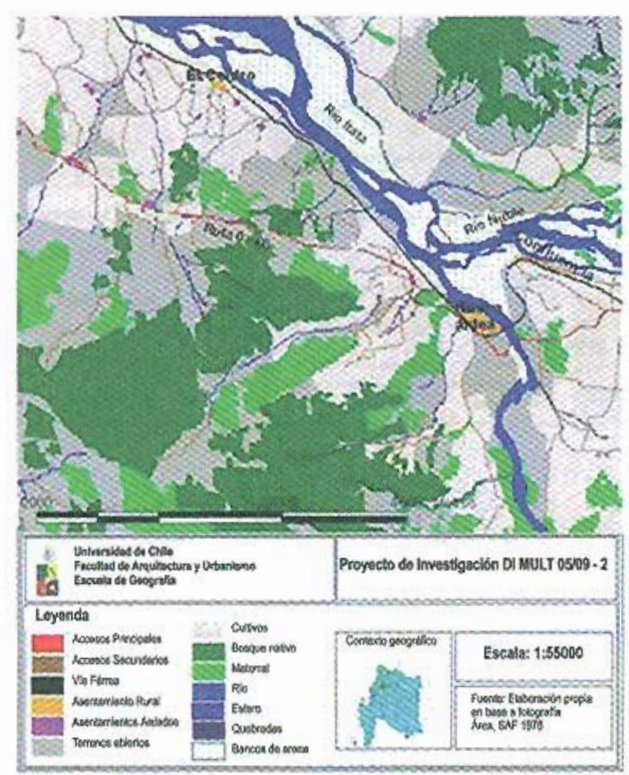

caminos locales.

$\mathrm{Al}$ observar la imagen de 1994 (Fig. 9.2), destaca la importantísima disminución de las áreas cubiertas con bosque nativo, aproximadamente $1 / 3$ de su superficie original, siendo sustituidas especialmente por plantaciones forestales, terrenos abiertos y matorrales. La figura 9.3, correspondiente a las coberturas existentes en 1998 demuestra que serán las plantaciones forestales las que sustituirán las áreas anteriormente cubiertas con bosques nativos y espacios abiertos desprovistos de vegetación. eran flanqueados en sus bordes por unidades ambientales degradadas, consistentes en matorrales de sucesión y espacios abiertos o áreas clareadas, como consecuencia del interés por introducir cultivos o ganadería. Los campos cultivados se distribuían a los largo de los bordes de esteros y ríos y de los

Figura 9.2 Usos y coberturas de suelos año 1994. Sector Nueva Aldea

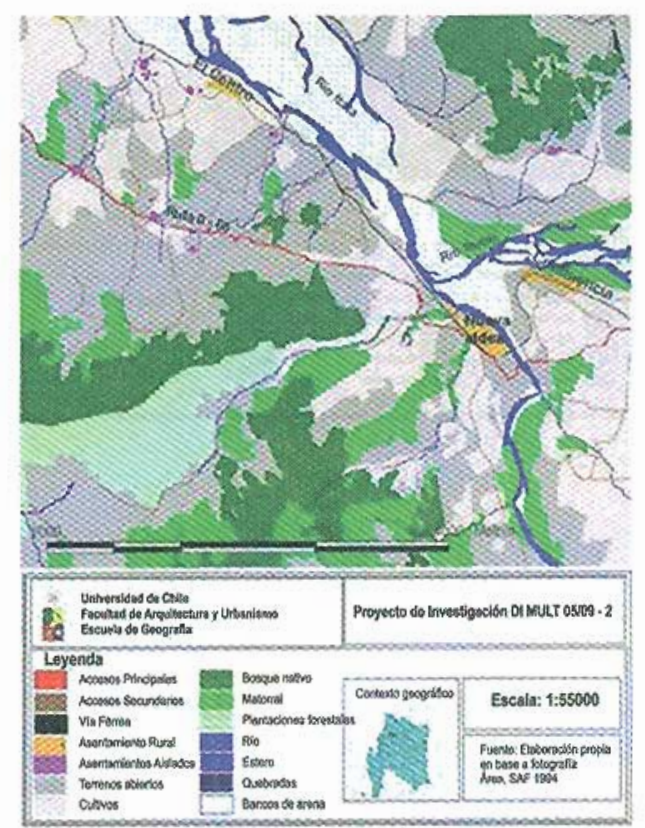

El año 2005 , en forma simultánea a la construcción del CFI, se aprecia que las plantaciones forestales han experimentado una gran expansión espacial, sustituyendo completamente al bosque nativo en los alrededores de la comunidad de Nueva Aldea, especialmente en las áreas contiguas a la ruta 152 , lo que señala la importancia que adquiere la accesibilidad en los cambios de usos de la tierra. 
Figura 9.3 Usos y coberturas de suelos año 1998. Sector Nueva Aldea

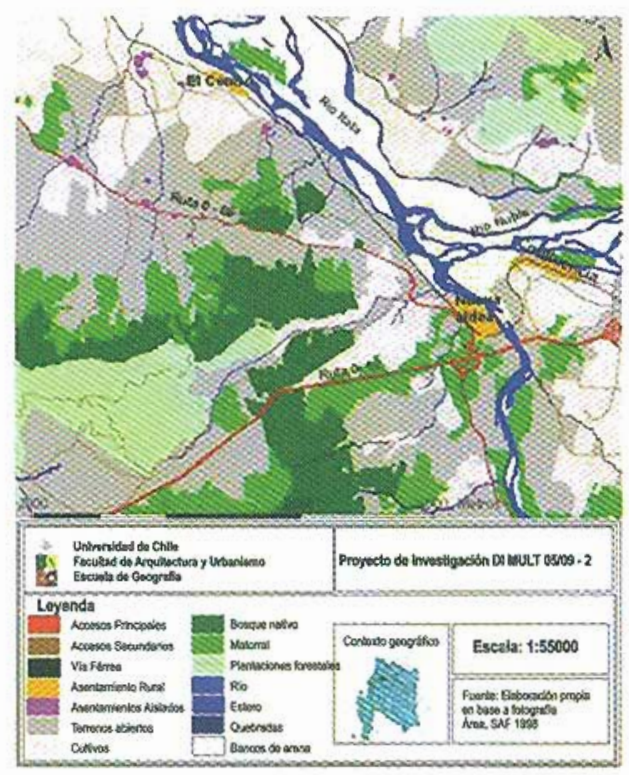

La comunidad de Guarilihue (Fig.10), presenta una evolución similar a la de Nueva Aldea, pero sus cambios pueden ser considerados de menor magnitud. La figura 10.1. permite observar que en 1978 predominaban pequeños parches de bosques nativos, intercalados con espacios abiertos, matorrales y escasas superficies cultivadas, otorgando
Figura 9.4 Usos y coberturas de suelos año 2005. Sector Nueva Aldea

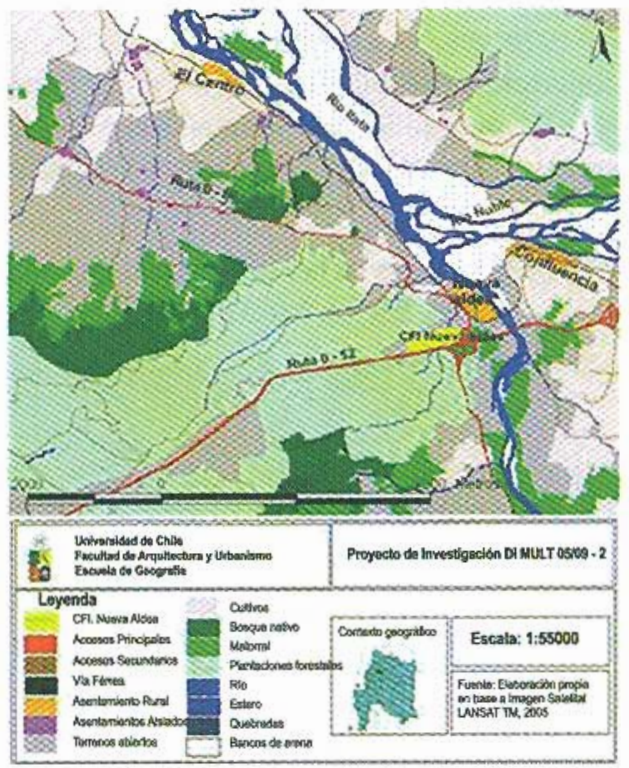

una morfología de gran fragmentación al paisaje. En 1994 (fig. 10.2.) se observa el aparecimiento de plantaciones forestales al W de la comunidad y a lo largo de esteros y caminos. La presencia de espacios forestales relativamente consolidados se había realizado a costa de la sustitución de parches de bosque nativo y espacios abiertos así como mediante la ocupación de tierras de cultivo.

Figura 10

Evolución de los usos y coberturas de los suelos en Guarilihue entre los años 1978 y 2005

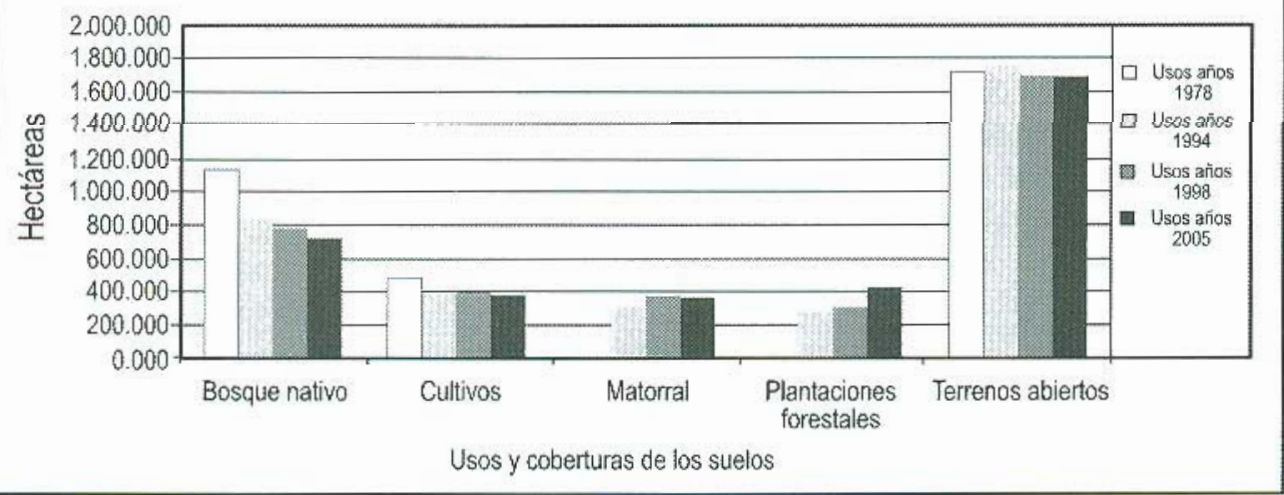

Fuente: Elaboración Propia 
Figura 10.1 Usos y coberturas de suelos año 1978. Sector Guarilihue

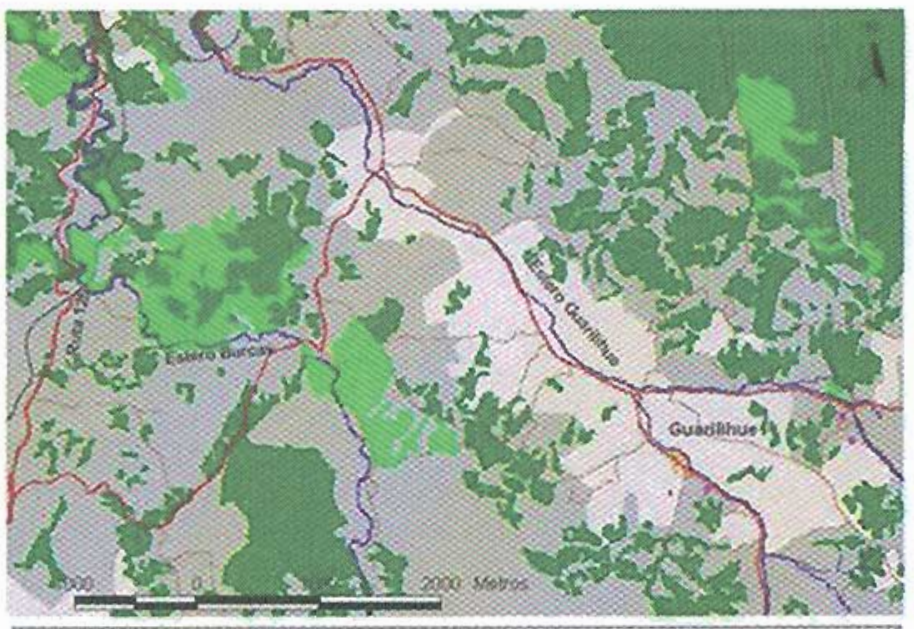

\begin{tabular}{|c|c|c|c|c|}
\hline हैy & \multicolumn{2}{|c|}{ 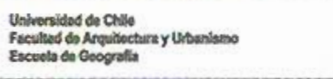 } & \multicolumn{2}{|c|}{ Proyecto de Investigación DI MULT 05109 - 2} \\
\hline \multicolumn{2}{|c|}{ Leyenda } & & & \\
\hline & Accescos Pinclpales & cosorestas & . & Escala: 1:55000 \\
\hline 2 & 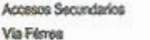 & 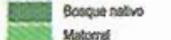 & & \\
\hline & Aserteriverto Runat & 2. costros & & 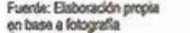 \\
\hline & Asertandionson Astados & 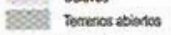 & & \\
\hline
\end{tabular}

Figura 10.2 Usos y coberturas de suelos año 1994. Sector Guarilihue

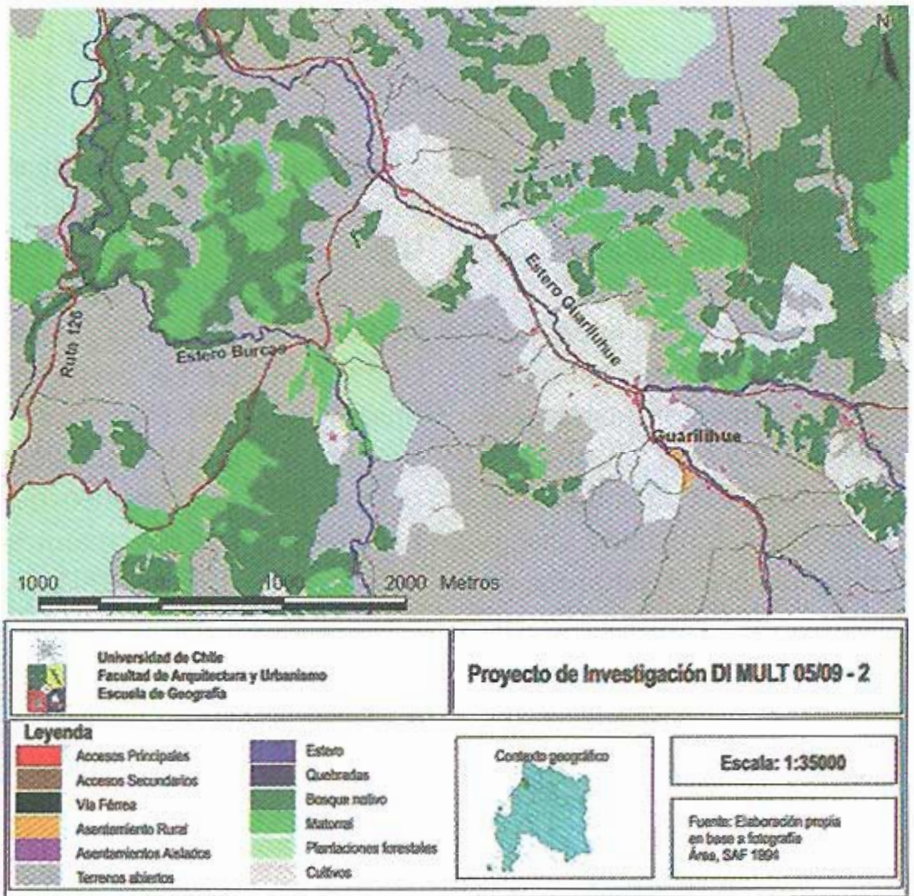


Figura 10.3 Usos y coberturas de suelos año 1998. Sector Guarilihue

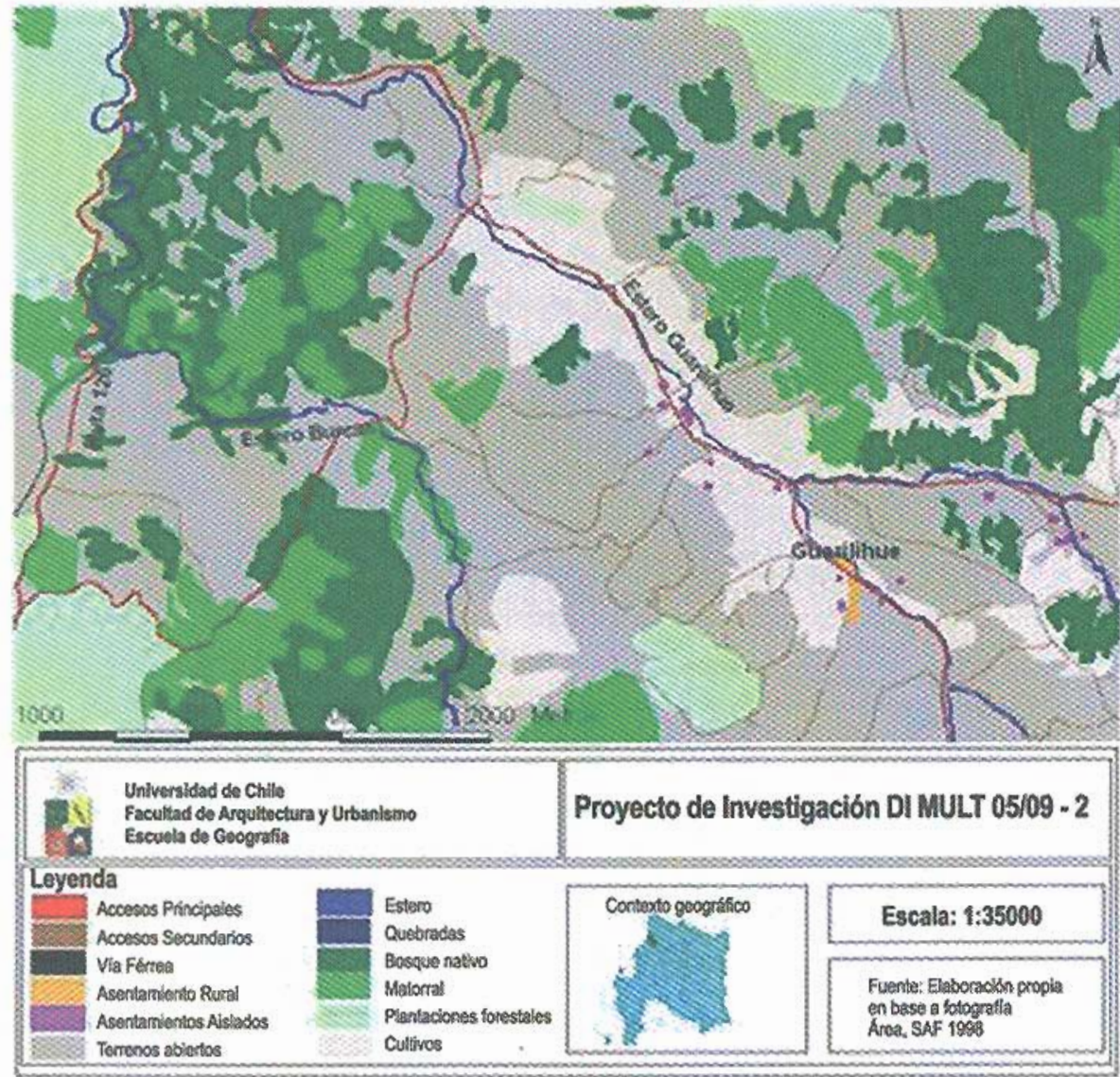

En 1998 (fig.10.3) se aprecia una consolidación de los usos forestales y se mantiene la reducción de las áreas con bosque nativo, lo que es más notable el año 2005 (figura 10.4.), cuando las plantaciones terminan cubriendo el borde $\mathrm{S}$ y W de los principales caminos, sustituyendo gradualmente los matorrales y las tierras abiertas. En este último año comienza a ser observada la sustitución de viñedos por plantaciones forestales, incentivada financieramente por la empresa de celulosa.

En el caso de la comunidad de Cerro Negro se aprecia una mayor estabilidad en las coberturas y usos de la tierra, en relación a los casos anteriormente mencionados (fig.11). En 1978 (fig. 11.1.) existía una gran homogeneidad en que predominaban los terrenos cultivados y las tierras abiertas. Como en todos los casos anteriores, en la imagen de 1994 (fig. 11.2.) aparecen por primera vez las plantaciones forestales que ocupan terrenos anteriormente cubiertos por bosques nativos, matorrales y espacios abiertos. En 1994 y 2005 (fig. 11.3 y 11.4) no se observan mayores cambios, ratificando la estabilidad que acompaña al desarrollo de esta comunidad. 
Figura 10.4 Usos y coberturas de suelos año 2005. Sector Guarilihue

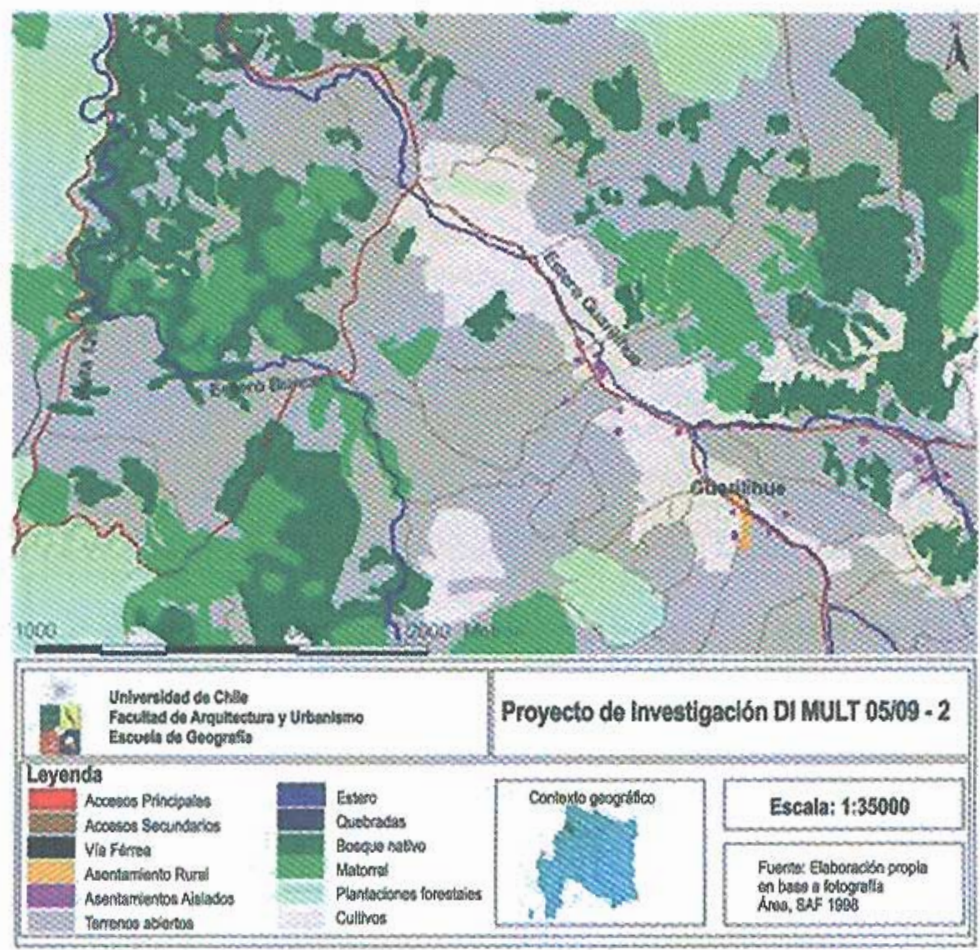

Figura 11

Evolución de los usos y coberturas de los suelos en Cerro Negro entre los años 1978 y 2005

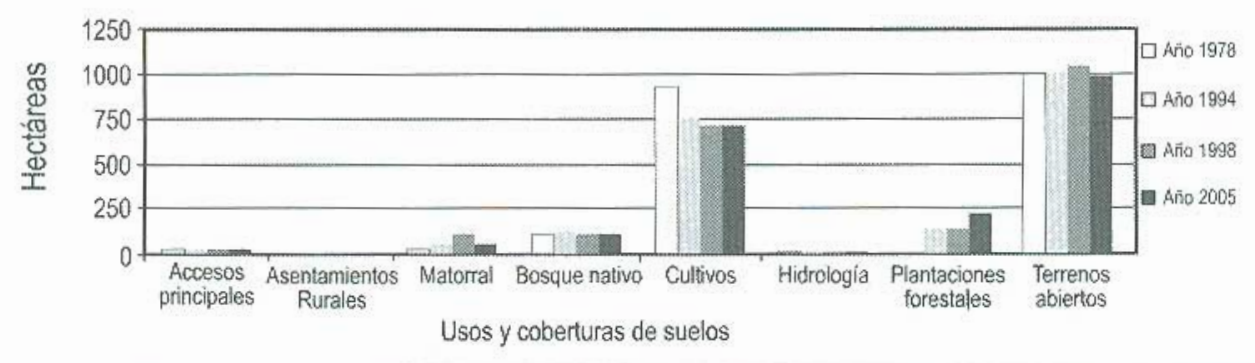

Fuente: Elaboración Propia.

Respecto a La Leonera, la figura 12 demuestra que las principales tendencias de cambio dicen relación con la disminución de las superficies con bosques nativos y el aumento de los espacios abiertos, que se han estancado los últimos años. La figura 12.1 demuestra que el espacio geográfico estaba completamente cubierto por bosque nativo, intercalando pequeños parches de matorrales y tierras abiertas. En 1994 (fig. 12.2) aparecen plantaciones forestales, localizadas especialmente a la orilla de caminos. Estas plantaciones forestales se irán generalizando en los períodos subsiguientes (fig. 12.3. y 12.4), precedidas por el reemplazo del bosque nativo por parte de terrenos abiertos y matorrales. 
Figura 11.1 Usos y coberturas de suelos año 1978. Sector Cerro Negro

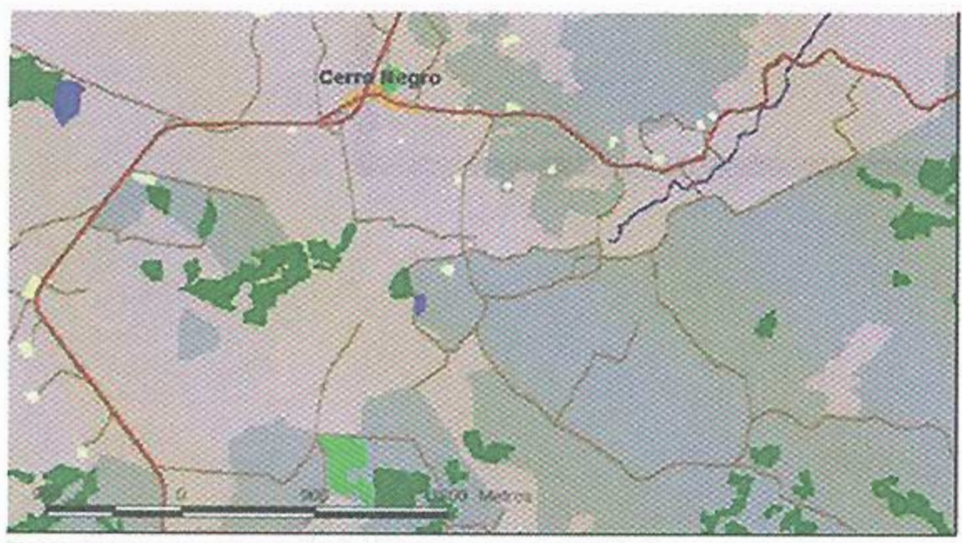

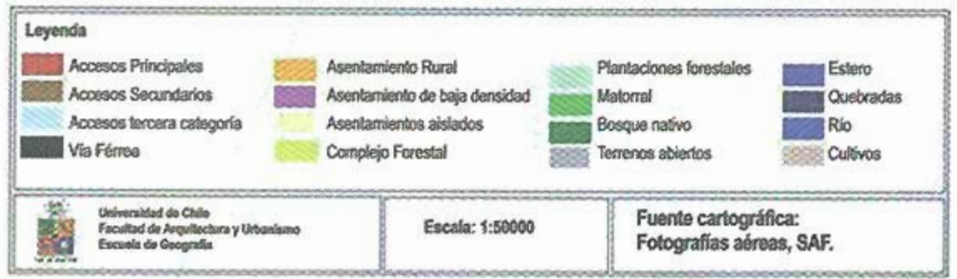

Figura 11.2 Usos y coberturas de suelos año 1994. Sector Cerro Negro

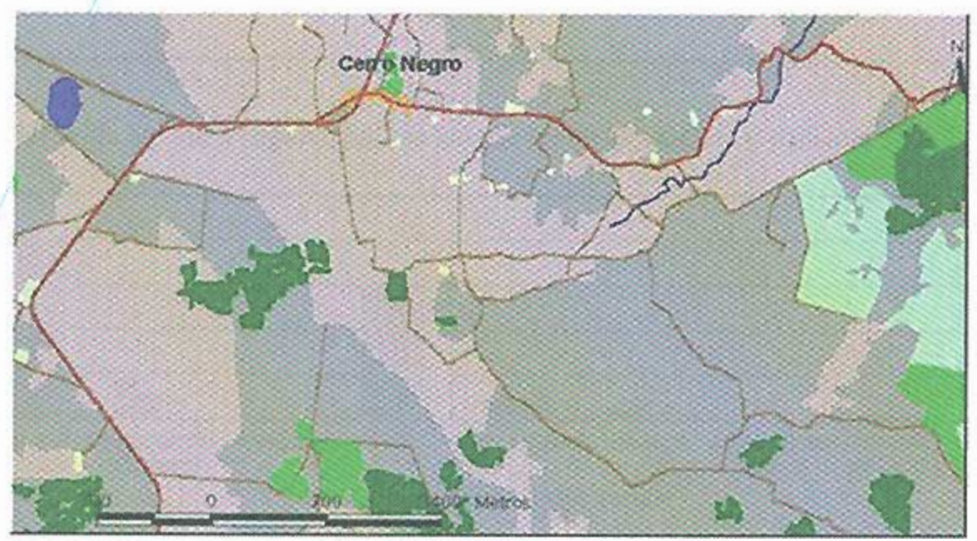

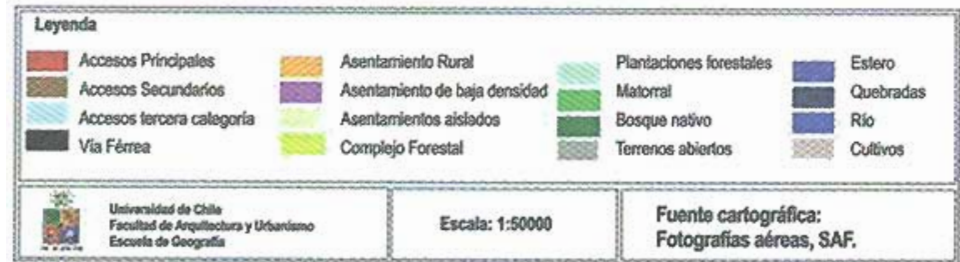


Figura 11.3 Usos y coberturas de suelos año 1998. Sector Cerro Negro

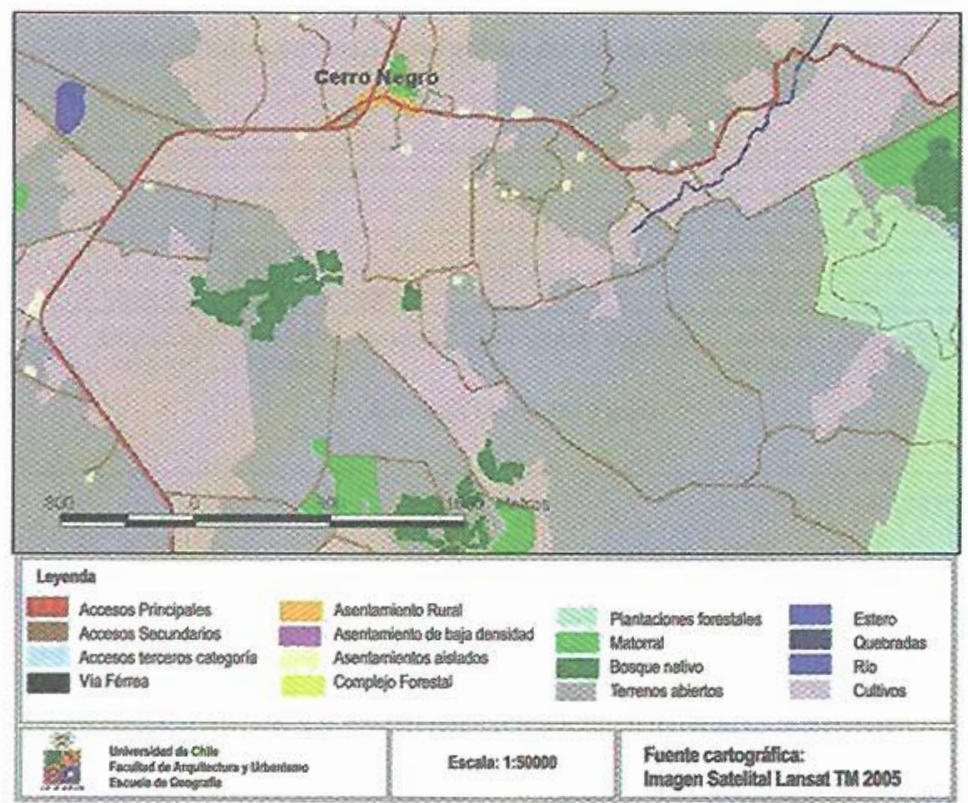

Figura 11.4 Usos y coberturas de suelos año 2005. Sector Cerro Negro

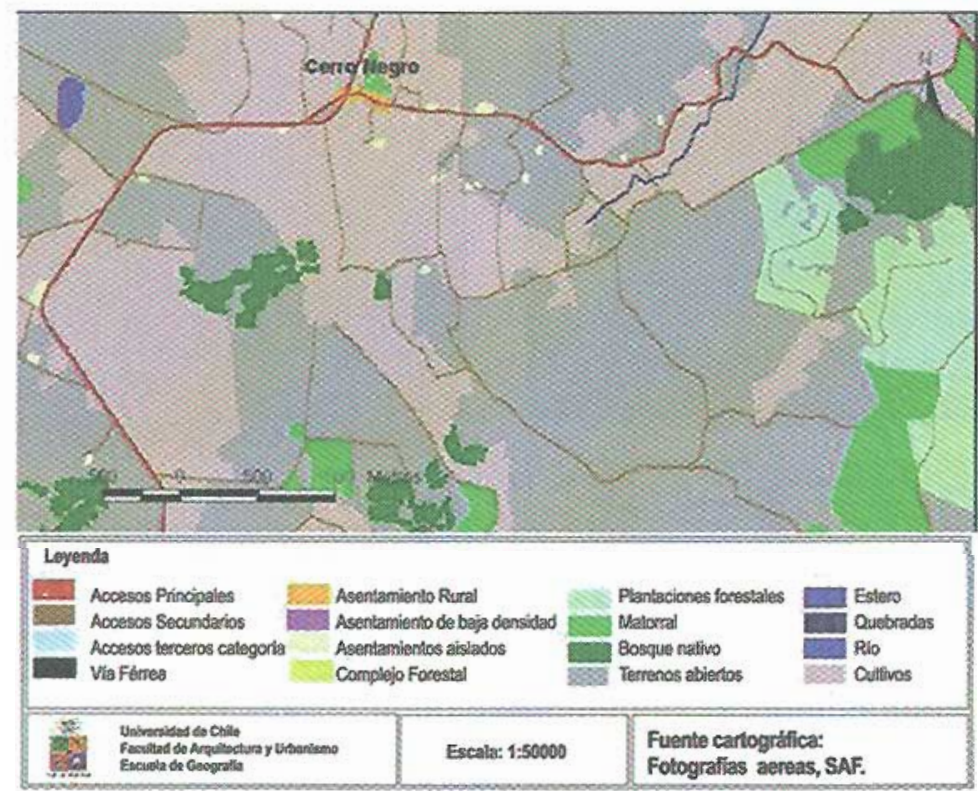


Figura 12.

Evolución de los usos y coberturas de los suelos en la Leonera entre los años 1978 y 2005

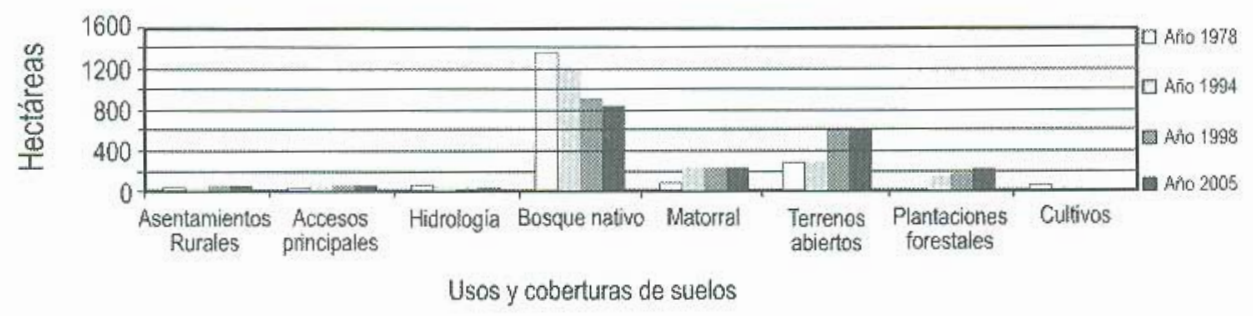

Fuente: Elaboración Propia

Figura 12.1 Usos y coberturas de suelos año 1978. Sector La Leonera

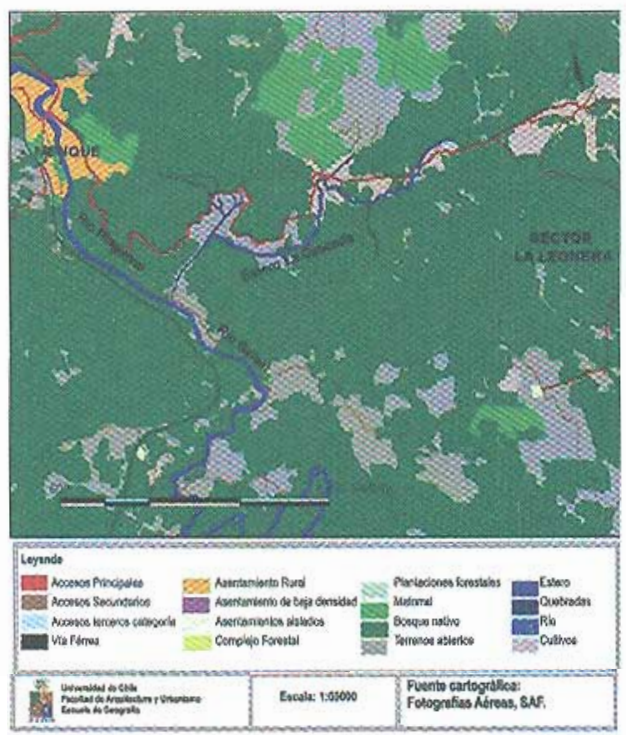

Figura 12.3 Usos y coberturas de suelos año 1998. Sector La Leonera

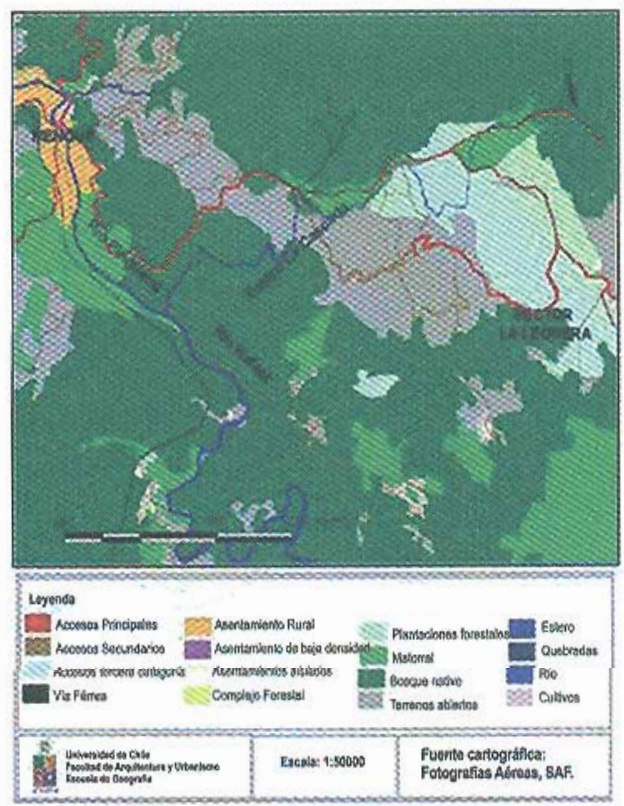


Figura 12.3. Usos y coberturas de suelos año 1998. Sector La Leonera.

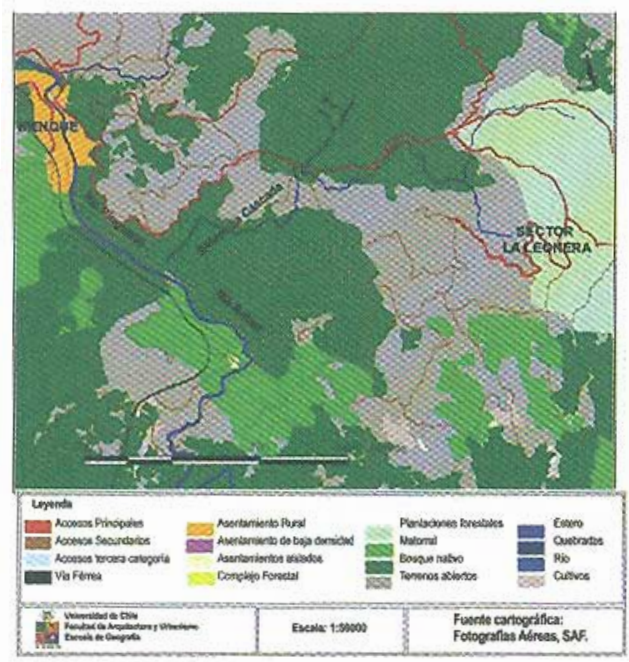

Figura 12.4. Usos y coberturas de suelos año 2005. Sector La Leonera.

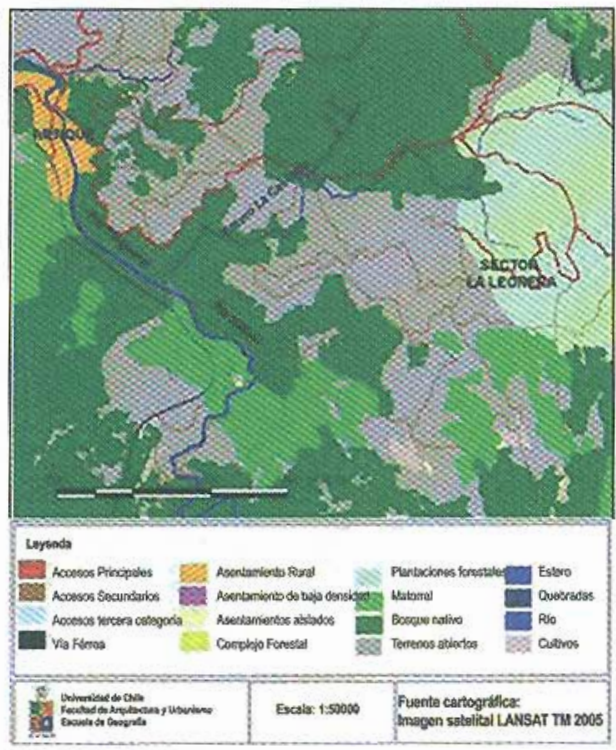

Análisis de los cambios en la accesibilidad

La naturaleza de enclave o nodos en redes que articulan las áreas productivas orientadas a los mercados globales con el territorio globalizado se manifiesta especialmente en la construcción de infraestructuras viales destinadas a conectar eficientemente las plantaciones forestales con la industria y a ambos con los puertos y centros de bienes y servicios. Romero y Órdenes (2003) analizaron los cambios en accesibilidad y conectividad causados por la construcción de caminos en el área forestal de Collipulli, concluyendo que se trata de nuevas oportunidades espaciales que exigen la gestión integrada del territorio local. Los caminos forestales y el mejoramiento de la accesibilidad significan no sólo beneficios para este sector, sino que además una revalorización de territorios que albergan ecosistemas y comunidades sociales de interés, junto con generar nuevas articulaciones que modifican la utilidad de los lugares. Todo ello es particularmente relevante en un país como Chile, dónde muchas de sus áreas rurales han permanecido con severos problemas de conectividad y accesibilidad a los centros abastecedores de bienes y servicios. Adicionalmente es importante mencionar que la utilidad de los lugares se ha visto fuertemente impactada por las tecnologías de comunicaciones que han terminado por eliminar el carácter de remoto que afectaba a muchos lugares en Chile.

Las figuras 13.1 y 13.2 presentan comparativamente la accesibilidad de Nueva Aldea los años 1978 y 2005. La construcción de autopistas, la pavimentación de caminos de tierra y el mejoramiento generalizado de los sistemas viales ha cambiado significativamente la potencialidad de acceso de esta comunidad, tanto a los centros urbanos mayores, como a las áreas rurales circundantes. Es posible apreciar como las áreas inaccesibles o de baja accesibilidad han casi desaparecido en este tiempo y cómo Nueva Aldea se ha constituido en un nuevo polo de centralidad en la red de comunicaciones regionales. 
Figura 13.1. Accesibilidad de Nueva Aldea año 1978

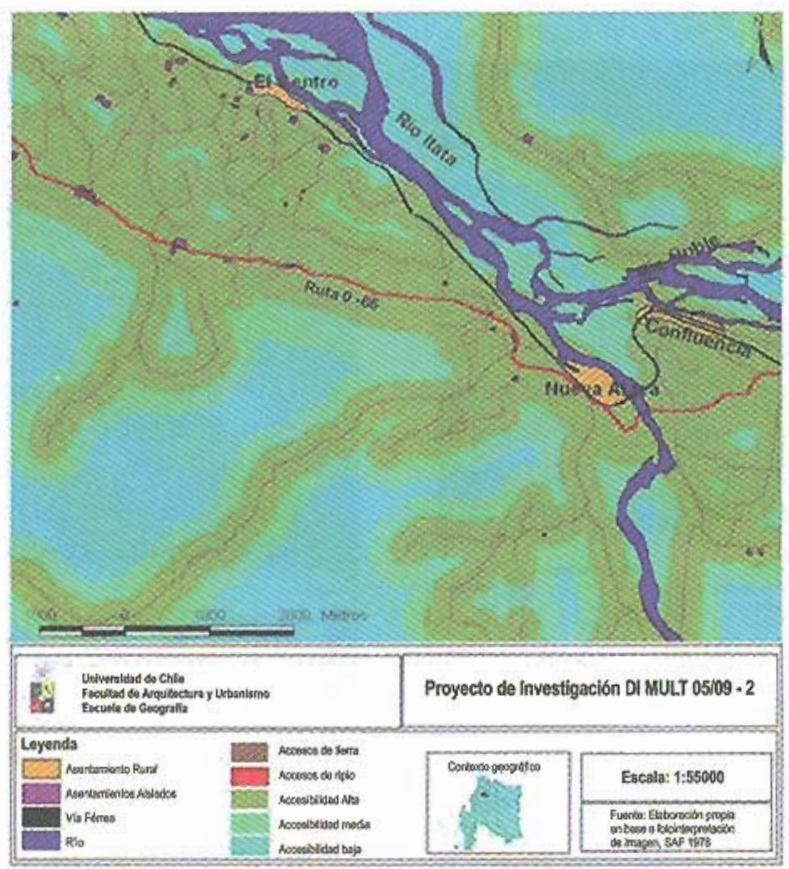

Figura 13.2. Accesibilidad de Nueva Aldea año 2005

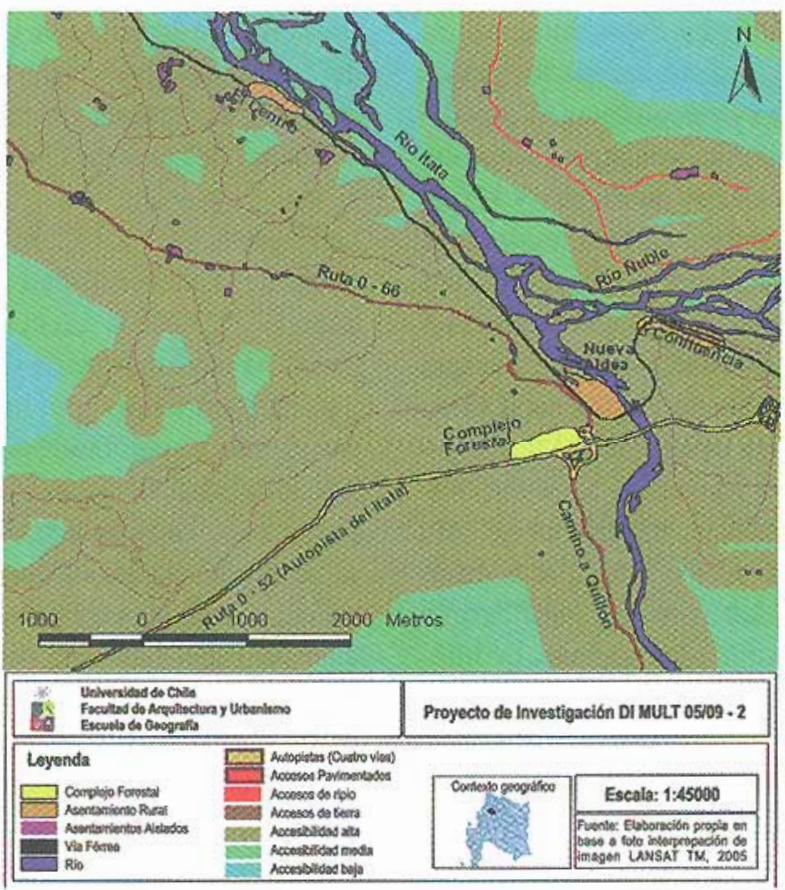


Las figuras $13.3,13.4$ y 13.5 presenta los cambios de accesibilidad que han afectado a Nueva Aldea, siendo notable el aumento de las áreas de alta accesibilidad, que pasan de 4561 a 6815 Hás., al mismo tiempo que las áreas de accesibilidad media y baja disminuyen de 2041 a 1591 Hás. y desde 2484 a 680 Hás., respectivamente. Estos cambios que demuestran el incremento de la conectividad entre los lugares puede acentuarse aún más en la medida que se realicen las obras viales proyectadas.

Los innegables beneficios asociados a la transformación económica de la utilidad de los lugares, como consecuencia de los dramáticos cambios en accesibilidad, deberían ser complementados con consideraciones de índole social y cultural y conformar planes y programas de desarrollo local integrado. Por ejemplo, la apertura cultural que implica una

Figura $\mathbf{1 3 . 3}$

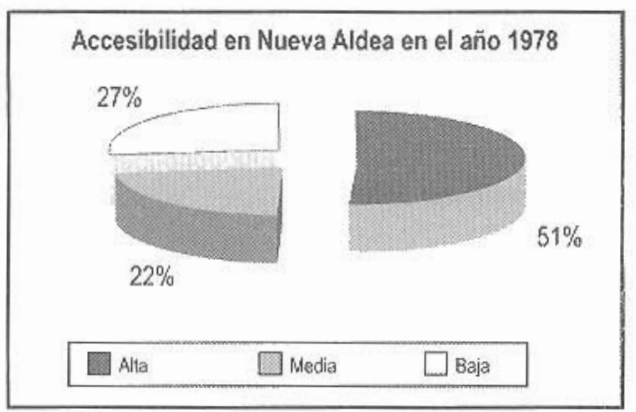

mejor accesibilidad, la creciente movilidad de los habitantes y la llegada de visitantes, debería ser resguardada y contrarrestada con el fortalecimiento de las actividades que contribuyen a una consolidación de la identidad local. Ello implica reconocer que en el caso de Nueva Aldea, se han abierto posibilidades enormes de complementariedad con las actividades que se localizan en las ciudades, metrópolis y pueblos cercanos y que alcanzan una expresión actual especialmente a través del turismo rural, que se transforma, en consecuencia, en una de las mayores expectativas para el desarrollo local. Sin embargo, el turismo rural es repelido territorialmente por la industrialización y la consiguiente contaminación del medio ambiente, y por la degradación de sus aspectos culturales como resultado del abandono de las formas de uso, tenencia y propiedad tradicional de la tierra, el agua y el paisaje.

Figura 13.4

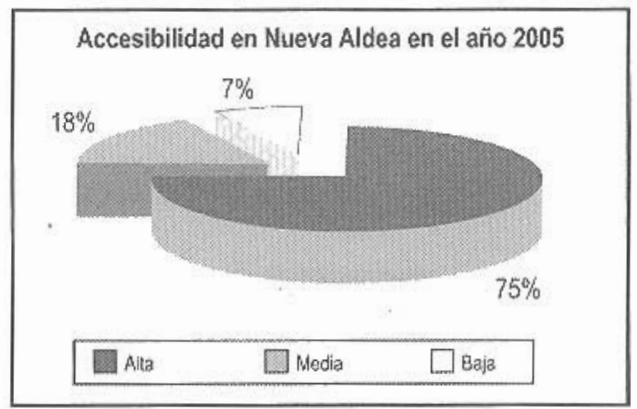

Figura 13.5

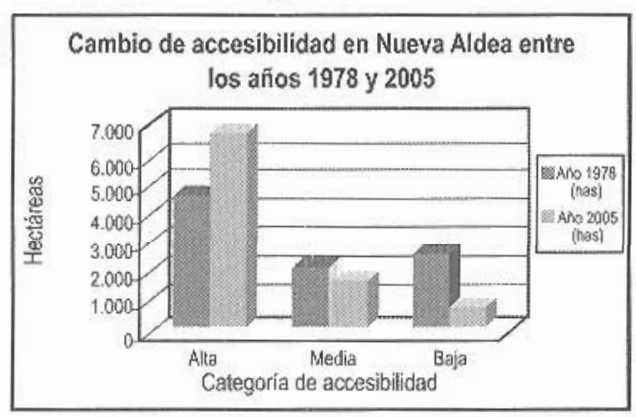

El caso de Guarilihue demuestra cabalmente el impacto positivo que resulta de los mejoramientos en la accesibilidad. La figura 14.1 señala que la distribución y estado de los caminos existentes en 1978 le otorgaba valores restrictivos de accesibilidad, predominando las áreas inaccesibles o remotas. La figura 14.2 permite visualizar los cambios relevantes ocurridos en la accesibilidad debido a la pavimentación y construcción de nuevas vías, que llegan a conformar un corredor de alta accesibilidad en torno a esta comunidad. 
Figura 14.1. Accesibilidad de Guarilihue año 1978

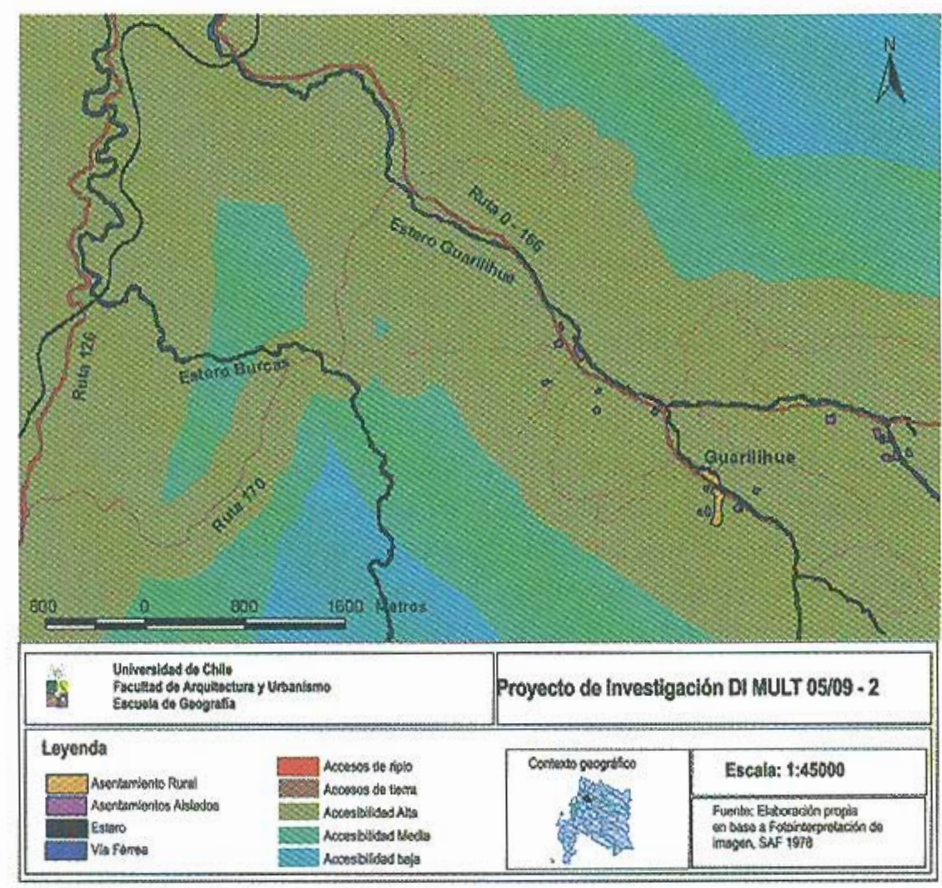

Figura 14.2. Accesibilidad de Guarilihue año 2005

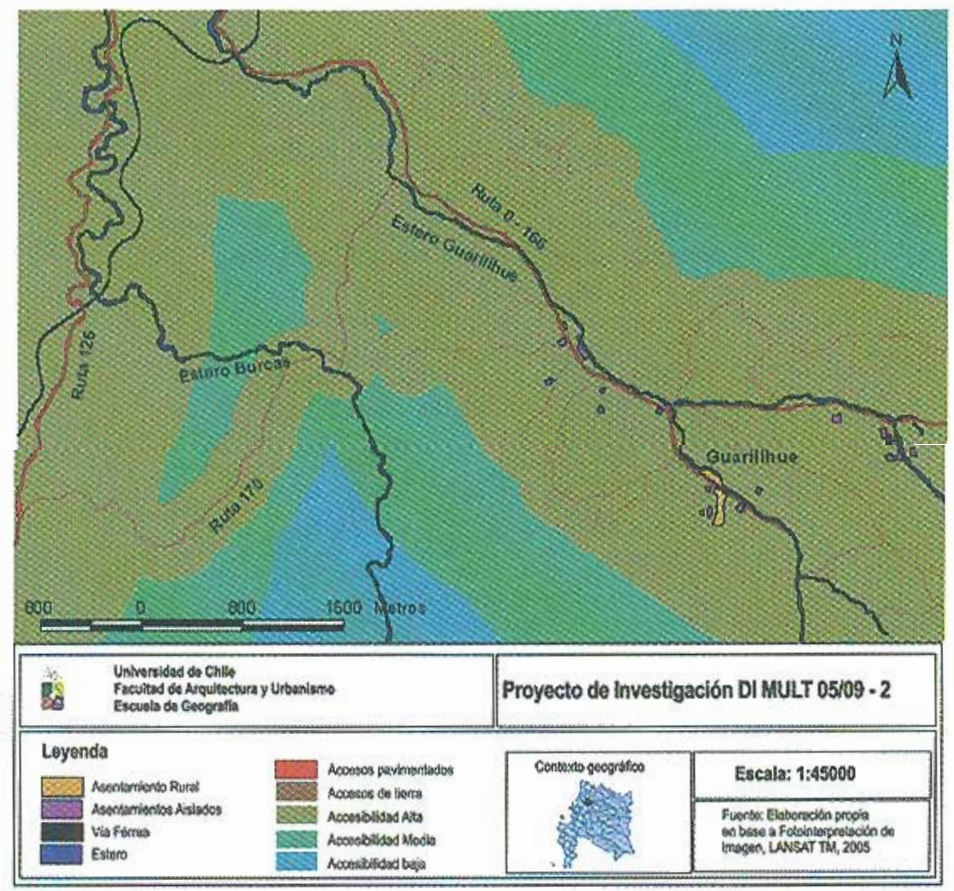


Figura 14.3

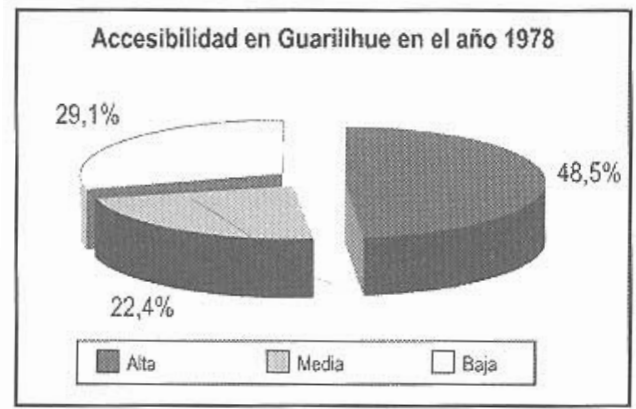

Figura 14.4

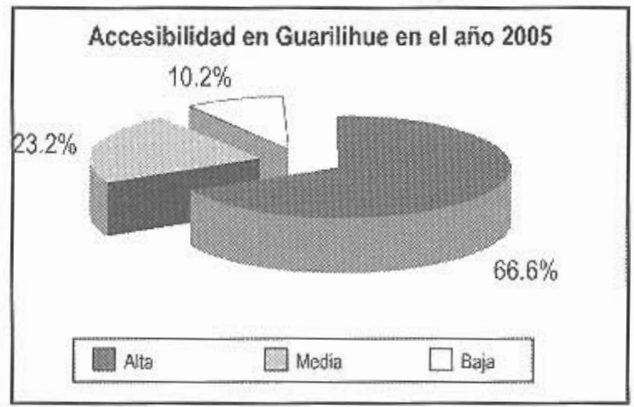

Figura 14.5

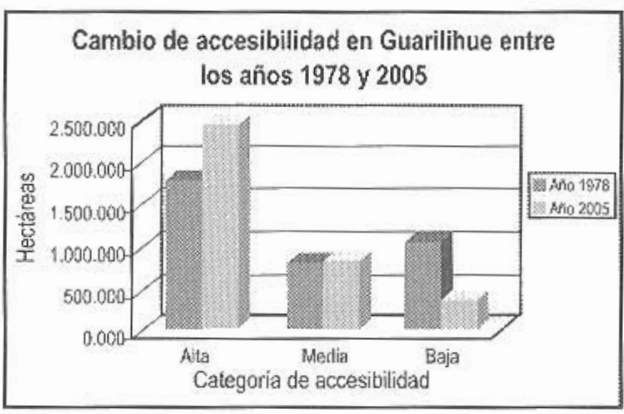

Las figuras $14.3,14.4$ y 14.5 representan el mejoramiento de las áreas de alta accesibilidad, que pasan de 1783 a 2449 Hás., mientras la accesibilidad media aumenta ligeramente (de 824 a 854 Hás.). La reducción más importante es experimentada por las áreas de baja accesibilidad, lo que implica que la conectividad de la comuna ha sido fuertemente mejorada.

El mejoramiento de la accesibilidad ha permitido el comienzo de una especialización novedosa para la comunidad consistente en la oferta de productos agroturísticos o de turismo rural. Visitantes especialmente provenientes del área metropolitana de Concepción arriban al territorio de la comunidad los fines de semana, para participar de un calendario anual de eventos gastronómicos $\mathrm{y}$ festividades, que han permitido aumentar y complementar los ingresos de las familias del lugar. Contando con el apoyo de instituciones públicas, las familias de Guarilihue organizan festividades que les permiten vender directamente sus productos agrícolas, gastronómicos, vitivinícolas y artesanales, a una demanda creciente, generando valiosas expectativas de desarrollo local comunitario (Romero et al., 2006). Sin embargo, el mayor temor de los actores locales es la contaminación ambiental, que a través de la pérdida de calidad del aire y de las aguas, o de malos olores, podría ahuyentar a los visitantes, al mismo tiempo que deteriorar definitivamente su base de recursos naturales. De no resultar posible la consolidación de las prácticas de turismo rural, es evidente que se acentuaría la pobreza y degradación cultural del área, obligando a sus habitantes a emigrar. No es de extrañar que esta comunidad haya sido pionera a escala regional en advertir las amenazas derivadas de la instalación del complejo industrial forestal en sus cercanías.

Por otro lado, la comunidad de Guarilihue forma parte de corredores de desarrollo turístico en proceso de consolidación, tales como la ruta del vino que asocia espacialmente a di- 
Cambios territoriales y efectos producidos por la industria forestal...

versas comunidades, y que se extiende a áreas vecinas cuyo complemento puede contribuir a complejizar y diversificar la oferta de eventos y productos, como sucede con los camarones de río y el turismo de playa en la comunidad de Vegas de Itata o las loberías marinas de Cobquecura. Estas dos últimas comunidades, localizadas sobre el borde costero, perciben como amenaza para su desarrollo turístico la construcción de un emisario marino de vertido de aguas contaminadas que podría afectar sus zonas de pesca y playas.

Las opciones de desarrollo de las comunidades rurales vinculadas al turismo de intereses especiales, demuestra la necesidad de avanzar desde la sustentabilidad de los proyectos a la sustentabilidad de los territorios en que se localizan los proyectos, buscando sinergias positivas que se traduzcan en beneficios comunes para los diversos vecinos, que representan escalas e intereses que pueden llegar a ser convergentes. Las inversiones en protección del medio ambiente natural y cultural y la existencia de vínculos virtuosos en el territorio no ha constituido hasta ahora un discurso preponderante, impidiendo la generación de actividades que resalten las ventajas de asociatividad espacial por sobre los conflictos o el apoderamiento exclusivo de los recursos críticos. Es decir un progreso en la generación y consolidación de complejos territoriales dinámicos.

Síntesis de los discursos de los actores involucrados en la instalación del Complejo Forestal e Industrial Nueva Aldea.

a) El análisis exitista de los empresarios

- El país y la región del BíoBío poseen una aptitud territorial esencialmente forestal que alcanza al $45 \%$ de la superficie total del primero y que asegura un potencial significativo de expansión a ambas escalas. El país y la región deben reconocer más explícitamente sus vocaciones forestales y adoptar proyectos nacionales y regionales en tal sentido como asuntos estratégicos

- El negocio forestal es altamente relevante en la gestión económica de la re- gión, atrae al 70\% de las inversiones de capital y se encadena productivamente con una gran cantidad de industrias y servicios, generando un amplio cluster y transformándose en el motor productivo indiscutible, que explica por sí sólo sobre el $30 \%$ de la actividad económica de la región.

- El sector forestal ha implicado un conjunto muy significativo de oportunidades de riqueza para una región que se encontraba históricamente en crisis con posterioridad al fracaso de los planes de industrialización pos sustitución de importaciones y debido a la degradación de sus recursos naturales.

- Las plantaciones forestales han contribuido a mejorar las condiciones del medio ambiente natural. Participan en primer lugar en la sustracción de carbono atmosférico y con ello efectivamente de la lucha contra el cambio climático; en segundo lugar, protegen los suelos erosionados y ayudan a su recuperacion; han eliminado la presión sobre los bosques nativos y con ello contribuido a su conservación y en la actualidad incorporan áreas y corredores cubiertos con especies nativas para asegurar la conservación de la biodiversidad y los hábitats de vida silvestre

- El efecto más significativo desde el punto de vista económico-regional se encuentra en las altas tasas de empleo que ofrece y que alcanzan a 60.000 puestos de trabajo directo en el caso de la región del BíoBío. A ello se deben sumar otros 120.000 empleos indirectos, con lo cual la actividad es la principal fuente laboral regional.

- La actividad forestal se encuentra en plena transformación productiva, reemplazando las labores puramente extractivas por industrialización, lo cual significa aumentar considerablemente el valor agregado a la producción. Dentro de las etapas de industrialización, destacan las ventajas de producción de celulosa, así como la fabricación de maderas aserradas, tableros y muebles. 
- La transformación industrial implica cambios en las demandas de calificación de la mano de obra, requiriéndose mayor especialización y aumentando los salarios, especialmente en comparación con los años anteriores.

- La empresa forestal posee y desarrolla un amplio concepto de responsabilidad social, que abarca desde su contribución al bienestar de la humanidad mediante la sustracción de gases invernadero, hasta la certificación del $70 \%$ de sus procesos productivos, para asegurar la no contaminación del ambiente, además de adoptar acuerdos de producción limpia.

- Las empresas forestales participan de planes específicos de compromisos sociales con las comunidades de las áreas en que se encuentran insertas, incorporando al negocio a pequeños y medianos propietarios de tierras, facilitando la reforestación de las áreas campesinas, y colaborando a la educación mediante la fundación y construcción de escuelas y parques educativos, programas específicos de formación profesional, acciones de pavimentación de calles y mejoramiento de las viviendas y paisajes urbanos de las ciudades en que se instalan,.

- El esfuerzo desarrollado en forma conjunta por los sectores públicos $\mathrm{y}$ privados han transformado a la industria forestal en una de las actividades de mayor alcance global y estratégico para el país, permitiendo la ubicación del mismo entre los principales productores y exportadores a nivel mundial, así como en nodo de importantes cadenas transnacionales, con inversiones en otros países de la región.

- Mantener y fortalecer el carácter global de las empresas implica la adopción de permanentes innovaciones en los terrenos productivos, tecnológico y de responsabilidad corporativa ante las sociedades locales. b) El discurso positivo del sector público

- En el caso de la Corporación Nacional Forestal se ha comprendido y desempeñado un rol de colaboración con el sector privado, en virtud del cual se han podido alcanzar los niveles de éxitos reconocidos unánimemente, afirmándose en la premisa de que "el éxito del sector pasa necesariamente por el éxito de los empresarios".

- La Comisión Nacional del Medio Ambiente reconoce que la actividad forestal constituye el rubro de especialización productiva más relevante de la región y uno de los pilares de desarrollo del país, lo que requiere una evaluación y planificación del sector de más largo plazo y mayor alcance conceptual y operacional.

- La ampliación conceptual implica reconocer que la actividad no sólo compromete a los bosques, sino que incluye relaciones con otros componentes de los ecosistemas naturales, tales como los suelos, las aguas y la biodiversidad. Adicionalmente, se trata de incluir en el análisis la gestión de los sistemas ambientales socio-económicos y culturales de las comunidades que se intervienen.

- La actividad forestal aporta la especialización regional que se requiere para insertarse en la sociedad global, y además participa de los desafíos de aportar mayor valor agregado a la producción, dado sus efectos sobre los salarios, el empleo y la pobreza.

- La actividad requiere mejorar sus relaciones con la sociedad regional y las comunidades locales, incorporando el cuidado del medio ambiente y la responsabilidad social como asuntos principales. Frente a lo primero, debe reconocer su dependencia de la conservación de los recursos naturales y ante la sociedad, la necesidad de actuar transparente e informadamente, contribuyendo a la construcción de 
confianzas, especialmente ante las comunidades con las cuales convive habitualmente y establece relaciones de vecindad.

- Entre los desafíos que enfrentan las empresas forestales ante la autoridad ambiental, destacan el incremento en el cumplimiento de las leyes, reglamentos y normativas que existen y que se irán desarrollando; el aumento de la capacidad de fiscalización de los organismos del estado para hacer cumplir los compromisos adquiridos en las evaluaciones de impacto ambiental de los proyectos; la incorporación efectiva de una nueva institucionalidad para la autorregulación de las propias empresas ante las obligaciones adquiridas; que se cumpla efectivamente con las leyes y se realice el mejoramiento de los sistemas de compensación por daños ambientales causados, y un incremento y perfeccionamiento en las estrategias de comunicación e información ante las comunidades y la sociedad, aumentando la transparencia, la construcción de confianzas y las acciones de buena vecindad; que se desarrollen e implementen nuevos instrumentos de gestión ambiental tales como ordenamiento territorial y gestión integrada de cuencas.

\section{Las preocupaciones del sector académico}

- Existe el convencimiento de que se dispone en la actualidad en el país de los conocimientos, modelos, conceptos y tecnologías adecuados para controlar la contaminación ambiental de los procesos productivos, adoptándose las mejores decisiones de acuerdo a la modernización del sector, el tamaño de la industria y los necesarios equilibrios financieros.

- La mayor preocupación que se observa dice relación con las relaciones entre las empresas, la sociedad nacional y regional y las comunidades locales. En gran medida la negativa percepción de la industria por parte de la sociedad deriva de la instalación de megaproyectos que no han considerado adecuadamente la dimensión social y la manera en que la concentración espacial de las actividades supera la capacidad de carga social de las localidades.

- La definición de la capacidad de carga social y la investigación de los factores que contribuyen a la negativa percepción de la actividad por parte de las comunidades indica la existencia de una asimetría entre los conocimientos disponibles para enfrentar los procesos industriales frente al desconocimiento de las relaciones sociales y culturales.

- Es necesario proponer la realización de "joint ventures" sociales, que reconozcan el papel activo de las comunidades y que sus actores sean incorporados efectivamente a la cadena de valor de la industria.

- El análisis del sector forestal ha sido realizado desde el punto de vista científico de una forma reduccionista, lo que ha impedido comprender las interacciones entre sus actividades, los medios receptores naturales y las relaciones sociales. No se han realizado análisis que den cuenta del desarrollo del sector como sistemas complejos.

- Es necesario proponer la realización de estudios que comprendan la totalidad del territorio afectado por las instalaciones forestales, por ejemplo a escala de cuenca, y que consideren en el análisis no sólo los impactos lineales e inmediatos sino que los efectos acumulativos en el tiempo y el espacio.

- Existen numerosas interrogantes científicas que resolver, tales como los impactos precisos de la contaminación de las aguas sobre el comportamiento de las comunidades biológicas, las relaciones entre los procesos ocurridos aguas arriba de las cuencas, los cauces fluviales y las áreas marinas contiguas; los impactos de los cambios globales del ambiente sobre los componentes locales o los efectos de la contaminación ambiental sobre la salud y la epidemiología de las poblaciones humanas. 
- En necesario introducir sistemas de evaluación ambiental complementarios a la evaluación de impacto ambiental de los proyectos individuales, relacionando las actividades forestales con la anticipación de los impactos acumulativos mediante la implementación de la Evaluación Ambiental Estratégica, la relación específica del desarrollo forestal con el desempeño de las dimensiones socio-económica y cultural mediante su asociación con las Estrategias de Desarrollo Regional y la preparación de planes de ordenamiento territorial que aseguren con anticipación la factibilidad de desarrollar nuevos proyectos, incluyendo la selección de su mejor ubicación en términos de los beneficios propios de la actividad como también de su compatibilización con las restantes actividades productivas.

- Respecto al desarrollo territorial del sector forestal, resulta evidente la carencia de instrumentos específicos, puesto que los planes reguladores comunales no incluyen sus áreas de localización, o los incluyen superficialmente a través de instrumentos de carácter indicativo como los planes regionales de desarrollo urbano. El análisis territorial no está dando cuenta de la complejidad de sus impactos sobre la generación de polos de desarrollo interiores (distintos a los tradicionales polos costeros), crecimiento de las ciudades y las infraestructuras y generación de nuevas redes de articulación espacial entre las áreas urbanas y rurales.

- Han surgido nuevas estructuras urbanoregionales que implican cambios en las jerarquías y funciones urbanas y en el poder y capacidad de articulación espacial de diferentes actores territoriales.

- Los cambios en el espacio socio-económico están significando perturbaciones de los sistemas culturales, incluyendo modificaciones en los patrones de identidad cultural y afectando severamente los elementos de arraigo al territorio local, representado por los sistemas de prácticas productivas, usos del suelo y sistema de valores de naturaleza local y tradicional. Han cambiado los paisajes naturales y socio-culturales y no se aprecia una evaluación de dichos procesos como tampoco una vinculación efectiva de las actividades forestales con otros componentes del desarrollo territorial tales como la producción y conservación de patrimonios, generación de viviendas típicas que representen la especialización productiva, imágenes urbanas que representen corporativamente a la actividad, vinculación con otras actividades rurales tales como el turismo y la recreación.

\section{Las diferencias en los discursos de los representantes municipales}

- Los representantes de comunas en cuyos territorios municipales las empresas forestales han estado presente por un largo período, manifestaron una amplia y profunda convicción favorable sobre el desempeño de las industrias, diferenciando "un antes y un después" a la instalación de las plantas de celulosa, e identificando al primer período con el atraso y la postergación y al más reciente con el progreso y el desarrollo.

- Entre los aspectos positivos mencionaron a la responsabilidad social de las empresas forestales manifestadas en la disponibilidad de puestos de trabajo- en especial en las etapas de construcción, las inversiones en mejoramiento de calles, viviendas y espacios públicos, la generación de eslabonamientos productivos con pequeños empresarios locales, tales como los abastecedores de alimentos y ropa de trabajo, y, esencialmente, los aportes al mejoramiento de la educación.

- Entre los aportes a la educación mencionaron la instalación de escuelas de alto prestigio y excelencia académica, abiertas a la totalidad de los escolares, la capacitación de profesores y el establecimiento de opciones educacionales técnico-profesionales, además de aportes en equipamiento educacional. 
- Igualmente se destacó la importancia de los mejoramientos urbanos sobre el desarrollo de actividades complementarias como el turismo, en la medida que los nuevos equipamientos e infraestructuras, así como los parques ambientales, los patrimonios industriales y la instalación de nuevos servicios y comercios, aumentaban la atractibilidad de los eventuales recursos naturales de que disponen.

- Las comunas asociadas al Valle del Itata, que están siendo directamente afectadas por las instalaciones del Complejo Industrial Forestal, fueron más enfáticas en la división entre un "antes y un después", afirmando que se encuentran aún viviendo la primeras de estas etapas. El antes lo caracterizan con el desarrollo forestal que se ha llevado a cabo en sus territorios comunales por los últimos 30-40 años y que se ha traducido en niveles de pobreza que alcanzan al $35 \%$ de las poblaciones locales. El cuadro esencialmente negativo, lo relacionan con una visión egoísta y ausente de la empresa, que ha resultado en emigración de las poblaciones rurales y desaparecimiento de comunidades, erosión del patrimonio cultural, deterioro de los recursos naturales y contaminación ambiental.

- No ha habido, a juicio de estos actores, una comprensión cabal del fenómeno de transformaciones territoriales asociadas al sector forestal, entre otras razones por la falta de interlocutores válidos, lo que ha repercutido en la carencia de visiones de futuro y un generalizado rechazo por parte de las comunidades que representan.

- $\quad$ El diseño de un después depende en consecuencia de una nueva institucionalidad que se plantee como objetivo el desarrollo sustentable del territorio y de los proyectos específicos, que fomente y practique la asociación entre actores y que se fundamente en un proceso de responsabilidad social de la empresa, que no debiera confundirse con filantropía empresarial ni paternalismos.
- Las comunidades locales deberían formar parte de los encadenamientos productivos de la actividad forestal industrial, aportando insumos en términos de productos y recibiendo los correspondientes beneficios económi$\cos$ y sociales. La "alfombra verde" es una definición de mesa de diálogo que convoca a los actores empresariales y locales para diseñar acciones conjuntas y participativas.

- Las nuevas formas de tratamiento del desarrollo local y territorial implican un cambio en el paradigma actual caracterizado por la exclusión y postergación de los intereses locales en beneficio de los intereses de los actores externos y de las empresas. El nuevo paradigma plantea relaciones de poder más simétricas entre los actores territoriales y un relevante respeto por los símbolos componentes de la identidad cultural local de las alternativas de desarrollo.

\section{CONCLUSIONES}

Tratándose de un proyecto de enormes proporciones, el CFI Itata se encuentra recién en su etapa de "marcha blanca" por lo que resulta prematuro evaluar sus reales efectos sobre las comunidades circundantes. Por lo demás y tal como lo demuestran los análisis practicados, las diversas comunidades examinadas venían presentando sistemáticas muestras de despoblamiento, abandono de tierras de cultivo y degradación de los bosques nativos, asociados a la pobreza y faltas de alternativas de desarrollo de los sectores rurales que forman parte del secano costero de la región del Bíobío.

El examen de los alcances espaciales de los cambios de empleo de mano de obra y cambios en los usos y coberturas de los suelos indican que en las imágenes de 1994 aparecen por primera vez las plantaciones forestales, vinculadas especialmente a tierras cercanas a ríos y esteros y accesibles por la red de caminos regionales. La población ha permanecido estable dentro de su escaso número y 
lo más relevante que exhibe es la dedicación de la antigua mano de obra dedicada a la agricultura en la comunidad de Nueva Aldea, a las labores propias de la construcción de las instalaciones industriales, que como se ha indicado, consiste en una actividad transitoria que seguramente no facilitará el regreso de la población activa a las antiguas faenas rurales.

Se podría afirmar que no se aprecian aún modificaciones substanciales en la estructura de usos y coberturas del suelo que pudieran denotar efectos relevantes de la construcción del complejo industrial y que los cambios presentan una función decaimiento-distancia que hace que sean más notorios en las cercanías más inmediatas. En general, las evidencias de decadencia y degradación de los recursos naturales y humanos parecen continuar sin mayores expectativas de cambios positivos. Sin discutir los efectos positivos sobre la economía y el empleo regional, es claro que la estructura reticular en torno a enclaves, que caracteriza a los megaproyectos, no consigue articular las áreas intersticiales que prácticamente permanecen estables. Si es importante relevar la importancia de los cambios en accesibilidad, ligados a la construcción de vías modernas de circulación de bienes y servicios, especialmente en la medida que cambia la utilidad de los lugares y con ello abre expectativas de generar alternativas de desarrollo tales como el turismo rural o el trabajo fuera de los predios agrícolas.

El análisis de los discursos permite avanzar en la identificación de significativos acuerdos y desacuerdos entre los diferentes actores o campos sociales que están interviniendo en las discusiones relacionadas con la instalación y funcionamiento del nuevo complejo forestal e industrial forestal del Valle de Itata. Los argumentos permiten considerar algunos de los elementos y conceptos críticos que enfrenta la discusión y prever las direcciones que asumirán los actores en el futuro e inferir los conflictos que se generarán.

Entre los conceptos más empleados se encuentra el observar y analizar al desarrollo forestal como un sistema complejo en sus aspectos naturales y socio-económicos y no insistir en la reducción de los análisis y los problemas a asuntos meramente técnicos y circunscritos a la operación de la industria y sus tecnologías. Los desafíos planteados por el funcionamiento de las empresas forestales deben ser analizados respecto a las transformaciones que producen en los sistemas territoriales, conformados por componentes físicos, químicos y biológicos, comandados por directrices biogeofísicas y socio-económicos-culturales, que representan intereses sectoriales y contradictorios. Parte de esas contradicciones se relacionan a la no necesaria integración de los actores, objetivos e instituciones de escala global, regional y local.

La planificación integrada de las cuencas, los planes de ordenamiento territorial y la evaluación ambiental estratégica destacan entre los instrumentos institucionales que están resultando necesarios para anticipar la localización de los proyectos, predecir los impactos acumulativos en el espacio y en el tiempo, y desarrollar perspectivas multisectoriales de actividades que por su importancia, crecimiento y alcance estratégico, van configurando escenarios complejos de desarrollo regional y local, que no pueden ser absorbidos por visiones parciales y puntuales o por instrumentos tales como la evaluación de impactos ambientales de proyectos.

Existe una concordancia muy amplia entre los diferentes actores sobre la necesidad imprescindible de incluir a las comunidades locales y regionales en las diversas fases de desarrollo del sector. Sin embargo, es evidente que no es posible reconocer avances conceptuales significativos sobre el reconocimiento de los campos sociales, las redes que los conforman, sus diferentes escalas de actuación y por ello, sobre las acciones específicas y conjuntas que habría que implementar. Más allá de la información que se espera poner a disposición de las comunidades por parte de la empresas, y por sobre las estrategias comunicaciones que éstas adopten, es evidente que los intereses de las comunidades debieran implicar una 
real y efectiva participación en los procesos de tomas de decisiones de los asuntos que afectan directa e indirectamente sus intereses de permanencia y desarrollo en el territorio.

Esto último genera un desafiante escenario institucional, puesto que la participación de las comunidades en la elaboración, planificación e implementación de planes, programas y proyectos de desarrollo, no existe en el país en la actualidad, por lo que se carece de los arreglos institucionales que lo permitan. Los desafíos actuales llaman al diseño de organizaciones e instituciones específicamente dedicadas a dirigir, planificar, implementar y coordinar acciones de desarrollo local, incluyendo las inversiones correspondientes y asegurando la representación de los actores en la toma de decisiones.

Ello plantea la necesidad de abrir la discusión más allá del sector forestal, puesto que en la formulación e implementación de planes de desarrollo local y regional corresponde la participación de otros sectores ígualmente relevantes del quehacer económico, social y ambiental, así como un conocimiento detallado de las políticas públicas.

$\mathrm{El}$ intento de reconocer la existencia de complejos dinámicos no ha encontrado respuesta en las evidencias y los actores comprometidos. El capital está orientado directamente a aumentar la competitividad global de las empresas y no a generar opciones de desarrollo local. Los cambos sociales se perciben sectoriales y sólo asociados a un nivel de análisis, ya sea global o local. No se aprecia con nitidez la existencia de redes y campos sociales que estén contribuyendo a la integración de escalas y objetivos. Por el contrario, es posible reconocer la preeminencia de intereses meramente sectoriales y los intentos por doblegar a otros actores mediante diversas fórmulas e instrumentos. No se están necesariamente generando las confianzas que posibiliten la integración de campos sociales que son realmente indispensables para desarrollar el concepto de anclaje.

\section{REFERENCIAS}

Bebbington, A. (2001), Globalized Andes? Livelihoods, landscapes and development. Ecumene 2001, 8 (4): 414-436.

Bozzanno H. (2000). "Territorios Reales, Territorios Pensados, Territorios Posibles: Aportes para una teoría territorial del ambiente". Editorial Espacio, Buenos Aires, Argentina. 374 pp.

Claval P. (2003), Geografía Cultural, Editorial EUDEBA, Buenos Aires. 360 pp.

Conti, S. (1997), Independent and unuven development. A systematic view of the globallocal dialectic. International Geographical Union Bulletib 47 (2): 195-205.

Powell, P.J. and DiMaggio, W.W. (eds.) (1991), The new institutionalism in organizational analysis, Chicago University Press. $280 \mathrm{pp}$.

Falcao Vieira, E.. y Falcao Vieira, M.M (2003), Espacios Geoeconomicos. Geoestrategia, Poder e Gestão do Território. Editora Sagro Luzzato, Porto Alegre, Brasil. 135 pp.

Foucault, M. 2003, Archaoelogie of Knowledge, Routdledge, London. 380 pp.

Floysand, A. \& Jacobsen, S.E. (2002), Clusters, social fields and capabilities: Rules and restructuring in Norwegian fish processing clusters. International Studies of Management and Organization. 31, 36-57.

Floysand, A. (2005), The Spatial Embeddedness of Foreing Direct Environment. Investigating the complex dynamics of FDI for power, regional development and poverty in developing countries. Department of Geography, University of Bergen, Norway. $18 \mathrm{pp}$.

Hägerstrand, T. (2003), A look at the political geography of environmental management. Sustainable Landscapes and Lifeways. 
Scale and Apropriateness. Edited by ASnne Butimer. Cork University Press, Ireland: pp. 35-58

Jacobsen, S.E., Rusten, G. and Floysand, A. (2005). How green is the valley?. Foreign direct investment in two Norwegian industrial towns. The Canadian Geographer: 49 , 224-259.

Neumann, I. (2001), Mening, Materialitet, Makt: En infooring i diskursanalyse. Fargbokforlaget, Bergen. 25 pp.

Pickett, S., Cadenasso, M. L. and Grove, J.L. (2004), Resilient cities: meanings, models and metaphor for integrating the ecological, socioenomic and planning realms. Landscape and Urban Planning 69: 369-384.

Parra, O. y Acuña, A., Editores (2006), Seminario 2005, La Industrial Forestal en la Región del Bíobío. Visiones desde distintas perspectivas. Universidad de Concepción, mayo 2006. $180 \mathrm{pp}$.

Romero, H. (2001), La Geografía de comienzos del siglo XXI: de la homogeneidad global a la diversidad local. Revista de la Asociación Nacional de Profesores de Geografía de la República de Uruguay, 16 (23) 13-29.

Romero, H. y Ordenes, F. (2003), El impacto de la forestación y la necesidad de la Evaluación Ambiental Estratégica en el Desarrollo Territorial del Sur de Chile. El caso de Collipulli. Revista Tiempo y Espacio. 10 (13): 15-33.

Romero, H. (2004), Perspectivas Estratégicas de Desarrollo Sustentable para las Montañas Andinas a partir del Estudio del Norte de Chile. Conservación y Desarrollo de los Ecosistemas de Montaña. Ministerio de Relaciones Exteriores, Comercio Internacional y Culto, República Argentina: pp. 11-33

Romero, H. y Azócar, G. (2004) Nuevos territorios forestales y perspectivas de desarrollo regional. In Desafíos Tecnológicos, territoriales, socioeconómicos y ambiental del desarrollo foestal industrial chileno. Oscar Parra y Adolfo Acuña (Editores), Concepción, pp. 27-46.

Scott, A.J. (1995), The geographical foundations of industrial performance, Competition \& Change, 1:51-66.

Serón, J. (2006), Pasado, Presente y Futuro de la Realidad Forestal e Industrial de la Región de Bíobío. Seminario 2005, La Industrial Forestal en la Región del Bíobío. Visiones desde distintas perspectivas. O.Parra y A. Acuña, Editores. Universidad de Concepción: pp. 11-27.

Vallega, A. (2000), Geography of diversitythe 21st century change. In Geografía para el Tercer Milenio. José Luis Palacio-Prieto y María Teresa Sánchez Salazar (Editores), Instituto de Geografía, Universidad Nacional Autónoma de México, pp. 17-36 